\title{
Flexibility Mechanisms and Pathways to a Highly Renewable US Electricity Future
}

\author{
Bethany A. Frew ${ }^{\mathrm{a},}$, Sarah Becker ${ }^{\mathrm{b}}$, Michael J. Dvorak ${ }^{\mathrm{c}}$, Gorm B. Andresen ${ }^{\mathrm{d}}$, and Mark Z. \\ Jacobson $^{\text {a }}$ \\ ${ }^{a}$ Department of Civil and Environmental Engineering, Stanford University, Stanford, CA \\ ${ }^{\mathrm{b}}$ Frankfurt Institute for Advanced Studies, Goethe University, 60438 Frankfurt am Main, \\ Germany \\ c Sailor's Energy, Corpus Christi, TX \\ ${ }^{\mathrm{d}}$ Department of Engineering, Aarhus University, 8000 Aarhus C, Denmark
}

\begin{abstract}
This study explores various scenarios and flexibility mechanisms to integrate high penetrations of renewable energy into the United States (US) power grid. A linear programming model POWER - is constructed and used to (1) quantify flexibility cost-benefits of geographic aggregation, renewable overgeneration, storage, and flexible electric vehicle charging, and (2) compare pathways to a fully renewable electricity system. Geographic aggregation provides the largest flexibility benefit with $\sim 5-50 \%$ cost savings, but each region's contribution to the aggregate renewable portfolio standard (RPS) target is disproportionate, suggesting the need for regional-and-resource-specific RPS targets. Electric vehicle charging yields a lower levelized system cost, revealing the benefits of demand-side flexibility. However, existing demand response price structures may need adjustment to encourage optimal flexible load in highly renewable systems. Two scenarios with RPS targets from $20 \%$ to $100 \%$ for the US (peak load $\sim 729 \mathrm{GW}$ ) and California (peak load $\sim 62 \mathrm{GW}$ ) find each RPS target feasible from a planning perspective, but with $2 x$ the cost and $3 x$ the overgeneration at a $100 \%$ versus $80 \%$ RPS target. Emission reduction cost savings for the aggregated US system with an $80 \%$ versus $20 \%$ RPS target are roughly $\$ 200$ billion/year, outweighing the $\$ 80$ billion/year cost for the same RPS range.
\end{abstract}

Keywords: renewable energy integration; energy system analysis; aggregation; storage; transmission; electric vehicle charging

\footnotetext{
${ }^{*}$ Corresponding author. Tel.: +1 650721 2650; fax: +1 6507237058
}

E-mail address: bethany.frew@alumni.stanford.edu 


\section{Introduction}

Electric utilities, load balancing areas, and transmission providers across the US are increasingly managing larger penetrations of renewable energy and engaging in greater regional coordination. This is driven by (1) policy, such as renewable portfolio standard (RPS) targets, Federal Energy Regulatory Commission (FERC) orders, and emission regulations, (2) reliability requirements, and (3) economics, such as declining wind and solar costs. As the electric sector continues in this transformation, there is a growing need for inter-regional analyses to determine the most costeffective plan for interconnecting large geographic areas with high penetrations of renewable energy generators. Such power system planning studies have been completed for various spatial extents in the US, e.g., PJM using the RREEOM model [1], Western US using the SWITCH model [2], and contiguous US using the ReEDS model [3], as well as in Europe, e.g., ENTSO-E grid with the URBS-EU model [4] and broader European extent including portions of Asia and Africa [5]. Other studies have focused on the operation of the system, such as NREL's Eastern [6] and Western [7] Integration studies, as well as more specialized operational studies that look at finer temporal resolutions (e.g., frequency response and transient stability in the Western US [8]).

Throughout these planning, grid integration, and detailed operational studies, various flexibility mechanisms have been identified to help mitigate the variability and uncertainty challenges arising from an increasing penetration of variable renewable generation. These include aggregation of supply, demand, and reserves through transmission interconnections; storage technologies; flexible generation, such as flexible natural gas turbines and the improved used of hydroelectric assets; demand flexibility, such as "smart grid" technologies and other demandside mechanisms to curtail and/or shift demand; overgeneration of renewable energy sources; new loads, such as electric vehicle charging; and markets and regulatory structures that enable system flexibility. In this study, four of these flexibility mechanisms are considered: (1) geographic aggregation through an enhanced transmission network, (2) overgeneration of renewable energy sources, (3) storage, and (4) new partially flexible load from electric vehicle charging. The last two items, storage and flexible load, contain similar time-shifting benefits. Numerous studies have shown that the second item, renewable overgeneration, will be necessary in highly renewable electricity futures, even when other flexibility options are available. Examples of these include a study of California with up to a 50\% RPS [9], a highly renewable PJM system [1], a highly renewable Australian system [10], and an energetic cost comparison of curtailment with and without storage [11]. Overgeneration has the potential to provide value to other systems instead of being shed, but such value streams are not considered in this analysis.

This work contributes to the growing field of power system modeling and analysis of highly renewable electricity systems by first introducing a new cost optimization planning model of the ten FERC regions in the US with highly-resolved wind and solar sites, and then using the model for a variety of applications and analyses. This model is validated against other established planning models, and a sensitivity analysis is performed at multiple geographic extents. Model applications include a thorough evaluation of the cost and overgeneration trends across five penetration levels of renewables, from 20 to $100 \%$ RPS targets, to demonstrate various transitions to a fully renewable system either for a regional California system or a national US electricity system. The impact of various pathways to a fully renewable US system is also 
considered across these same RPS targets. This study also provides a more holistic view of the least-cost optimization of the power system by quantifying the health and climate cost savings of avoided fossil-based emissions.

However, to the best of our knowledge, the most novel contribution of the results presented here is the systematic and comprehensive analysis of the four flexibility mechanisms identified above. Other studies have demonstrated the benefits of some flexibililty mechanisms individually (e.g., storage in Ireland [12] and aggregation in the Western US [13]), shown synergistic or competitive relationships between two different options (e.g., storage and flexible load in ERCOT [14], storage and overgeneration in the Western US [15], and storage and overgeneration from various countries and technologies in the literature [11]), or demonstrated preliminary additive benefits of multiple flexibility solutions for a single region (e.g., [9]). This study extends the existing body of literature by quantifying and comparing the cost-benefits of a more complete and systematic set of combinations of flexibility options for multiple geographic extents. For example, the quantitative benefit of cooperation among regions is highlighted in these results comparing individual regions to a corresponding aggregated group of regions. Finally, the effects of PEVs are thoroughly examined to provide additional insights into the flexibility benefits of electric vehicle charging, and more generally, of flexible load and the need to shift generation spatially or temporally.

\section{Cost minimization model of US electric system}

\subsection{Model overview}

POWER - Power system Optimization With diverse Energy Resources - is a linear programming model designed for high-level planning of the contiguous US electric power system. As such, it can be used to evaluate the effects of combining diverse renewable and conventional power generators to match electric load across the ten FERC regions. The model includes the integration of renewable generators, storage, and transmission, and extends upon previous work, which focused on the effects of aggregating electric load alone [16]. POWER deterministically solves for the least-cost portfolio of generators, storage, and transmission that meet the electric load in each time step while attaining a given RPS target.

POWER has the capability to handle an hourly chronological temporal resolution for a full year temporal extent. However, due to computational constraints, the results presented here are based on a representative subset of days; this generally consisted of 14 days for the US, 28 days for the Western Electricity Coordinating Council (WECC - comprised of AllCA, SW and NW regions), and 56 days for California. See Section 4.10 in [17] for a discussion and justification of these subsets. This temporal treatment is consistent with nearly all existing nationwide or large regional renewable energy integration models which consider a similar subset of hours (e.g., NREL's ReEDS model [18]; NEMS EMM [19]; EPRI's US-REGEN (initial model description [20] with addition description and policy application [21]); and UC Berkeley's SWITCH model 
(initial model version for California in [22] and extension to the Western US in [2], with additional details in [23])).

POWER was built in AMPL, a high-level mathematical programming language [24], and solved with CPLEX [25]. It includes a representation of generators (baseload, dispatchable, and variable), storage, and transmission, with a statistical characterization of operating reserves. The model uses hourly wind and solar data across thousands of sites from 2006, historical hourly demand data from 2006 by FERC region, other regional renewable resource availability data, regional cost parameters and various system parameter inputs. Each system component has an annual cost that is a function of the amortized capital costs, which depend on the installed capacity decision variables, and the annual variable costs, which depend on the total annual generation or storage throughput. Figure 1 shows the schematic of POWER with each component, the optimization problem, and resulting outputs. A detailed model formulation with all sources for data and input parameters is given in Chapter 4 of [17]. Key data and input sources include NREL's Western [26] and Eastern [27] Wind Datasets, mesoscale-modeled wind fields for supplemental wind sites in the Southeast US [28], processed reanalysis wind data from NOAA/National Weather Service for additional wind sites in the Southeast US and ERCOT [29], technology costs from Black and Veatch [30], solar data from the National Solar Radiation Database [31], load data from FERC [32], hydroelectric system data from the Idaho National Laboratory [33], geothermal resource data from Massachusetts Institute of Technology [34] and United States Geological Survey [35], and PHEV profiles from the Electric Power Research Institute [36].

POWER determines the capacity of each system component and how those components are dispatched each hour. Wind and solar sites are evaluated individually, with a separate hourly time series dataset for each site for the hours within the given set of representative days. All other generators and storage technologies are aggregated spatially by FERC region. Additionally, there are optional submodels to include existing generators, generator retirements based on age and environmental regulations, and additional firm and flexible load from plug-in electric vehicle charging (PEV - assumed to include plug-in hybrid electric vehicles and electric vehicles). However, unless otherwise noted (e.g., pathways buildout in Section 4.2 or sensitivity analyses in Section 4.3), POWER ignores the existing generators and retirements and instead builds a new-from-scratch system for each scenario. Emissions from fossil fuel generators are also quantified.

All time series and existing system data are from the base year 2006, or as close to this year as possible. Exceptions include: existing transmission system capacity based on 2008 data, generator costs from 2013 values, fuel prices based on projected 2015 values, and PEV load estimated as year 2030 projections (but still applied to the 2006 demand and variable generator data). All cost data inputs and results were adjusted to the base year 2006USD to be consistent with the use of 2006 data. Data was collected from the year 2006 since this was the most recent year that wind, solar, and demand time series data were all available, so as to ensure timesynchronization of these datasets. However, POWER uses these single year data inputs to construct a future electricity system with no definite time stamp and, unless otherwise noted (e.g., pathways buildout in Section 4.2 or sensitivity analyses in Section 4.3), with no constraints 
imposed by the existing infrastructure (i.e., "greenfield" approach) except for the inclusion of existing transmission corridors.

In the work presented here, the RPS is defined as the fraction of total load met by all renewable resources. Many states have restrictions on the contribution of hydroelectric generators to that state's RPS, but this model assumes that all existing and any new hydroelectric capacity contribute fully to the RSP constraint.

Generator models in POWER include the baseload resources of run-of-river hydroelectric, nuclear, and geothermal; dispatchable resources of natural gas, coal, and conventional hydroelectric; and variable resources of onshore wind, offshore wind, large-scale photovoltaic $(\mathrm{PV})$, and residential rooftop PV. Dispatchable generators have decision variables for both installed capacity and hourly production, while baseload generators only have a decision variable for installed capacity, with hourly production based on that capacity de-rated by planned and forced outage rates (see Sections 4.4.1 and 4.4.2 in [17]). In addition, geothermal, hydroelectric, solar, and wind generator capacities are constrained by the maximum developable resource within each FERC region (see Sections 4.4 and 4.8 in [17] for details on these limits). Storage models in POWER include pumped hydroelectric storage, concentrating solar power (CSP) with thermal energy storage (TES), and battery storage. Each storage technology is characterized by energy conversion efficiencies into and out of storage and the losses during storage. Within each representative day, the model chronologically tracks the amount of storage going into, out of, and held in storage for each time step. To prevent seam issues from the use of non-consecutive representative days, all storage technologies must begin and end each day with the same amount of energy held within storage, with that energy level endogenously chosen by POWER. CSP is included only as a storage technology since all energy provided to meet load must first pass through the TES system; a direct path from incoming solar irradiance to loadserving electricity is not modeled.

The transmission topology from [16], shown in Figure 2, was used with a pipe-flow transmission model in POWER. Note that the FERC region CAISO is replaced with a modified full-California region named "AllCA". This network consists of a node at the geographic center of each FERC region and a segment connecting nodes between each adjacent FERC region. The approximate segment distances and significant existing inter-region transmission capacity were estimated from approximate FERC boundaries and GIS data of 2008 existing transmission lines [37], assuming 100 mile lines for the $\mathrm{kV}$-to-MW conversion. All $\mathrm{kV}$-to-MW line conversion values were taken from [38] except for $115 \mathrm{kV}$ lines, which used conversion values from [39]. This topology assumes full interconnection within each FERC region (i.e., "copper plate"). POWER also assumes fixed technology-specific generator and storage grid connection costs; however, the use of site-specific "spur" line connection costs has been found to influence capacity expansion model outcomes [40]. The transmission model solves for the additional required capacities and hourly transmission flows (bidirectional) for each segment. The segment capacities are assumed to be the maximum single hourly flow in either direction, adjusted for inter-regional transmission line losses. As noted in [16], the simplified topology and pipe-flow treatment likely underestimate the total transmission requirements, especially for FERC Regions with spatially dispersed load centers or areas of congestion. Since transmission line flows are shared according to Kirchhoff's laws in the actual AC transmission system, these simplifications also prevent 
POWER from fully capturing the interaction between transmission congestion and overgeneration (e.g., [41]). In future work, the impact of such congestion on the transmission and broader portfolio decisions within planning models, such as POWER, could be approximated with transmission supply curves using the methodology presented in [42] or the furtherdeveloped probabilistic version in [43]).

The reserve requirement model ensures that enough operating reserve capacity is available to provide sufficient flexibility for balancing load and generation at all times. Planning reserve requirements, which ensure that adequate generating capacity is available at all times based on peak load, are not explicitly included. The total operating reserve requirement is comprised of frequency regulation, contingency, and forecasting error reserve needs and must be met with a combination of spinning and non-spinning reserves, which are met by the available portions of eligible generators and storage technologies. Frequency regulation and contingency reserve requirements were approximated from load data and the single largest hazard within each region. Forecasting error reserve requirements were approximated as three multiples of the expected value of the unexpected standard deviation of forecast error in each hour aggregated across all wind and solar sites, assuming persistence-type forecasts. See Section 4.6 in [17] for details on the reserve requirement formulation.

Total annual system cost in POWER consists of the sum of generator, transmission, and storage costs. The generator costs include amortized capital costs, fixed and variable operations and maintenance (O\&M) costs, and fuel costs. The total generator costs depend on both the installed capacity and annual generated energy of each generator technology, as determined by the model. The transmission costs include the amortized line, substation, and asynchronous interconnection (i.e., AC-DC-AC interties across the Eastern, Western, and ERCOT interconnection boundaries) capital costs for additional transmission capacity requirements, which reflect the transmission line distances in Figure 2. Storage costs include amortized capital costs and fixed O\&M costs for both the power and energy capacity, as well as variable O\&M costs. Regional cost multipliers are applied to generators, storage, and transmission to capture regional differences in construction costs. Details of these cost parameters are included in Section 4.9 of [17].

By only focusing on the flexible load component of PEVs and how PEV demand impacts the integration of renewables, POWER ignores the full energy system benefits/costs from PEVs. These include fuel and emissions savings of PEVs relative to the gasoline internal combustion engine (ICE) vehicles that they are assumed to replace, the additional costs for enhancing grid infrastructure to enable charging PEVs, and the additional costs for acquiring PEVs. However, PEV total cost of ownership is projected to converge with other vehicle types by 2030 [44], and the PEV fleet size here is based on reasonable projections of fleet turnover to PEV in 2030 (see Section 4.8.1 in [17] for details). POWER assumes that any additional costs are outside of the study boundary and that all barriers to PEV adoption (e.g., consumer concerns regarding range anxiety and time to charge, installing adequate smart grid infrastructure to facilitate optimal charging, and developing a business model for providing charging services) will be overcome to achieve the given penetrations. Increases in power plant fuel and associated emissions from the additional PEV load are accounted for within the generator models in POWER. 
The least cost optimization in POWER is solved deterministically and simultaneously for all time steps using full knowledge of the historic electric load and modeled meteorological data. It thereby ignores uncertainty from forecasting errors, although as previously mentioned, an exogenous statistical treatment of reserve requirements due to forecasting errors is included. By design, the statistical model likely overestimates the negative effects of forecasting error uncertainty, which could affect the results. For instance, using deterministic methods (i.e., not including forecasting uncertainty) has been shown to underestimate the benefits of flexibility offered by storage [12], overestimate carbon emission abatement potentials by $33 \%$ [45], and overestimate system cost [46].

\subsection{Validation}

POWER was validated against three other power system planning models, each representing a different spatial extent. These include the Regional Renewable Electricity Economic Optimization Model (RREEOM) for the PJM region; the Solar, Wind, Hydro, and Conventional generation and Transmission Investment (SWITCH) model for the WECC region; and the Regional Energy Deployment System (ReEDS) model for the contiguous US. In the validation cases, both model and input data of POWER were modified to replicate, as best as possible, specific scenarios run by the three other models. Results from the validation runs aligned well with results from all three models and served as a satisfactory validation of POWER. The modifications and results are detailed in Section 4.11 of [17].

\section{Description of scenarios}

To evaluate (1) the effect of flexibility mechanisms and (2) a comparison of pathways to a fully renewable US electricity system, various scenarios were completed for the AllCA region, the WECC, and the contiguous US. Each model run evaluated one of five possible RPS target levels: $20 \%, 40 \%, 60 \%, 80 \%$, and $100 \%$. All results presented here assumed $5 \%$ intra-regional transmission line losses and 8 hours of storage duration. Existing and retiring generators were not considered. Unless otherwise noted, all results are based on the same original model formulation with modifications for utilizing a subset of days as presented in Chapter 4 of [17].

\subsection{Flexibility mechanisms}

POWER was run with various combinations of aggregation, storage, renewable overgeneration, and partially flexible PEV load to gain insight into the relative benefits of these individual and coupled flexibility options for both a single region (AllCA) and an aggregate area (WECC). The resulting cost tradeoffs are shown in Section 4.1.1 for a 40\% RPS target for AllCA (based on total annual levelized cost) and WECC (based on total annual system cost). Additional results are shown in Section 4.1.2 for AllCA at various RPS targets to gain better insight into the flexibility benefits of PEV load. Each of these scenarios are independent model instances with a new builtfrom-scratch system for each RPS target. Flexibility tradeoff results are not shown for RPS 
targets above $40 \%$ or for the contiguous US, as no solution exists for some of the flexibility combinations in these cases (infeasible solutions).

\subsection{Pathways to a fully renewable US system}

Three sets of additional scenarios, each with and without PEV load - for a total of six sets of scenarios - were run for each RPS target $(20 \%, 40 \%, 60 \%, 80 \%$, and $100 \%)$ to compare an incremental transition to a fully renewable US system against independent RPS target system buildouts. For example, are the same wind solar sites that are selected for an optimal $80 \%$ RPS target also developed at a 20\% RPS target? There may be value in looking ahead at the optimal system configuration for higher RPS targets when making investment decisions at lower RPS targets. Results for this comparison are shown in Section 4.2. The first set evaluated the sum of independent constituent FERC regions, the second evaluated the aggregated (interconnected) FERC regions, and the third evaluated the aggregated FERC regions with a "pathways" buildout, where each successive RPS target built off of the established renewable capacity of the previous RPS target. The corresponding avoided social costs from reductions in fossil-based emissions are also presented and compared against the total system cost required to achieve those savings.

For the pathways cases, the first RPS target (20\%) assumed that all existing 2006 FERC regional renewable generator and storage capacity (i.e., all but nuclear, natural gas, coal, and battery storage) was built and then determined the additional needed least-cost capacity. As discussed in Appendix A, the CSP store-in constraint was relaxed to allow for curtailment of incoming solar energy in these runs. For all successive RPS targets in the pathways cases, the model required renewable generator and storage capacities to meet or exceed the previous RPS target capacities, including site-based wind and solar farms. Conversely, non-renewable generators and storage capacities could be chosen at any level, regardless of the previous RPS target capacities, to reflect either additional capacity installations or unit retirements.

\section{Results}

\subsection{Flexibility mechanisms}

\subsubsection{Cost tradeoffs in AllCA and WECC at 40\% RPS}

Venn diagrams of all possible combinations of flexibility mechanisms were used to summarize the cost tradeoffs between the four different flexibility mechanisms at a 40\% RPS target. For AllCA, Figure 3 summarizes the total levelized cost (in 2006USD/MWh of unit load served) and the percent cost savings relative to the no flexibility case (i.e., no renewable overgeneration, storage, or PEV load) for each combination of renewable overgeneration, storage, and PEV. Geographic aggregation was not considered for AllCA since it is a single region. Levelized costs were used in order to normalize results across scenarios with different load requirements (i.e., the PEV scenario has to accommodate a larger overall load). Figure 4 shows similar results, but with all four flexibility mechanisms, for the WECC region. Since only three flexibility mechanisms 
can be fully compared with Venn diagrams, these four flexibility mechanisms were split into cases with (green, right) and without (blue, left) additional PEV load. In each of these Venn diagrams, the darker the shading, the greater the relative cost savings.

These Venn diagram results revealed symmetries in cost savings. The benefits were partially additive, which agrees with preliminary findings from E3's study of California [9], and were dominated by one or two flexibility mechanisms. For an individual region (AllCA), storage and PEV dominated. For an interconnected region (WECC), aggregation and storage dominated.

Overall, of the flexibility mechanisms considered, geographic aggregation through an enhanced transmission network had the greatest system cost benefit, providing about $5 \%$ cost savings. This benefit was even more pronounced when coupled with storage; renewable overgeneration added little benefit on a cost basis. Additional WECC model runs with POWER (see Section 5.1.1. in [17]) revealed that aggregation offered greater cost savings (about 13\%) at an $80 \%$ RPS target. Another US-wide study found similar 5-10\% cost savings due to geographic aggregation [47].

Storage alone had a smaller benefit than aggregation, but results suggest that storage is a necessity for RPS targets $\geq 60 \%$. All AllCA model runs, both with and without overgeneration and with and without additional PEV load, were infeasible if storage was not permitted at these higher RPS targets. These results are supported by finding from Denholm et al. [15], which showed that curtailment and the subsequent need for storage becomes significant when a western US system achieves about $40-50 \%$ of annual electricity production from variable renewable generators. Power system planning studies that focus on high penetrations of renewables should therefore include storage, and as discussed in Section 4.10 of [17], should carefully model storage with the proper temporal treatment.

Overgeneration of renewable energy sources can be considered a flexibility mechanism, with the potential to provide value to other systems, such as district heating or driving irrigation pumps, instead of being shed. These additional value streams were not included in this study. As mentioned in Section 1, overgeneration of renewables is expected to be significant as the penetration of renewables increases, typically resulting from transmission congestion, lack of transmission access, or excess variable renewable generation during times of low demand when conventional units cannot turn down any further because of minimum run constraints or to maintain system frequency requirements [48]. Solutions to minimize overgeneration therefore include enhancing the transmission network and removing any institutional barriers to accessing that network, properly incentivizing flexible generator capacity and the participation of that capacity when needed, and the flexibility mechanisms evaluated here. While renewable overgeneration contributed the smallest cost savings of the flexibility mechanisms evaluated here, results indicate that it is necessary for high RPS scenarios; many model runs of AllCA $\geq$ $60 \%$ RPS were infeasible when overgeneration of renewable energy sources was not permitted. POWER found that renewable overgeneration (versus otherwise identical runs with no overgeneration permitted) yielded the least-cost solution in AllCA runs with an RPS above 20\%, which is consistent with a recent California RPS study [9]. 


\subsubsection{Benefits of PEV at additional RPS targets in AllCA}

With an RPS target of 40\% for AllCA, PEV's offered a modest benefit (Figure 3). In this section, the benefit is evaluated for various RPS targets up to $100 \%$. Figure 5 shows the total annual system cost breakdown and renewable overgeneration with and without additional PEV load. In addition, Table 1 quantifies the relative increase in total system cost and renewable overgeneration due to PEV, for both cases with overgeneration (as shown in Figure 5) and without overgeneration.

Three key observations can be made from these results. First, a fully renewable AllCA system is feasible with the given model assumptions, but at significant cost and overgeneration of renewables; the $100 \%$ RPS cases had over twice the total annual system cost and over three times as much renewable overgeneration as the $80 \%$ RPS cases. More work is needed to determine if and how this last $20 \%$ should be achieved. A greater focus on demand-side flexibility instead of the dominant supply-side-only investments presented here may be a more economical pathway to achieve a fully renewable electricity system.

Secondly, overgeneration from renewable energy sources becomes drastically more prevalent at high RPS targets. The renewable overgeneration results for AllCA align well with results from the E3 California RPS study [9], which found upwards of $12 \mathrm{TWh} /$ year overgeneration at $50 \%$ RPS. The $80 \%$ RPS results presented here correspond to roughly $57-58 \%$ RPS without hydro resources (California only allows $\leq 30 \mathrm{MW}$ hydro units in certain situations to contribute to the RPS target - see [49]), with about 18-22 TWh/year overgeneration. In a related analysis for California, Hart and Jacobson [45] demonstrated the significant increase in generator capacity that is required for greater levels of renewable generation penetration; for a roughly $65 \%$ increase in annual generation from 2005 (about 40\% carbon-free) to 2050 (about 65\% carbonfree), the California electric system required over a $165 \%$ increase in total generator capacity. However, while the $100 \%$ RPS renewable overgeneration quantities presented here are large ( $25-30 \%$ of the total annual load, both with and without PEV), these are significantly less than the least-cost solution for $\geq 90 \%$ of renewable energy in a PJM regional study [1], with renewable overgeneration of at least $200 \%$ of total electrical energy required.

Third, PEV always had a slightly larger total annual system cost due to the increased total load, but PEV also yielded less total renewable overgeneration for all cases above $20 \%$ RPS. Thus, PEV increases the system utilization of generation resources, especially wind and solar, with a proportionately smaller increase in total cost. This system utilization is also highlighted in the total cost and levelized cost curves (2006USD/MWh of load served) for PEV and non-PEV cases (Figure 6); the total annual levelized cost is always more expensive without PEV than with PEV and increasingly so at high RPS targets. Other studies have similarly found that PEV can facilitate the integration of variable renewables by increasing system utilization through load shifting [50] and reducing excess generation (e.g., shown throughout literature in a review paper [51], including a German 2030 scenario that found up to about 50\% reduction in curtailment with PEVs [52]).

It is important to note that this study only investigated the ability of PEVs to provide flexible load (i.e., taking energy from the grid to charge the PEV batteries), as such charging has been 
shown to be the primary flexibility resource of PEVs [50]. However, many studies have found additional grid flexibility benefits by supplying flexible stored energy to the grid through vehicle-to-grid (V2G) services [53], but this comes at the cost of increased battery life degradation. Furthermore, both the charging of PEV and any V2G services must be managed properly in order to minimize undesirable system impacts [54] and distribution system effects (e.g., power loss and voltage deviations [55], overloading of distribution lines [54], and loss of life of distributional transformers [56]).

As mentioned in Section 2.1, POWER does not account for the fuel and emission savings of PEVs relative to gasoline ICE vehicles. As an estimated comparison, the total annual PEV load in this study results in a four-to-five-fold savings in gross annual energy, had that PEV end use been met with gasoline ICE vehicles instead. For a fully renewable US system with PEV charging, the $114 \mathrm{TWh}$ /year annual electricity requirement for charging PEVs equates to 13.717.6 billion gallons of gasoline, or 474-611 TWh/year of gasoline fuel-equivalent input energy, based on the lower heating value of gasoline and a range of gasoline vehicle efficiency and battery electric vehicle efficiency values from [57].

The benefit that PEV provides the system with its flexible load highlights the importance of demand-side flexibility as the penetration of renewables increases. This flexibility can be provided with demand-side management, which broadly includes energy efficiency and demand response. With demand response, load (including new load from electrified sources, like PEVs) can be curtailed and/or shifted to better match the magnitude and timing of the variable renewable resource supply and provide greater reliability through ancillary services. Studies and electric utilities have shown the potential value of demand response through reducing the need for new peak capacity (e.g., as already observed through PJM's capacity market [58], as well as projections for future systems, such as a reduction of up to $20 \%$ by 2019 in a US study [59]), providing ancillary services (primarily contributing to operating reserve requirements, e.g., [60]), reducing ramping events (e.g., [61]), increasing baseload capacity (e.g., "valley-filling" capabilities as observed in [62]), and facilitating renewable energy integration (e.g., [60]). The results here only focus on the energy, and not reliability, benefits. The results here also echo conclusions from [63], which found that California's 2050 carbon targets cannot be achieved without aggressive energy efficiency and (among other measures) conversion of gasoline vehicles to smart-charging (flexible) PEVs; these measures were also found to significantly reduced the cost of a highly renewable California system.

The timing of the PEV flexible load, which was chosen by the model for the "optimal" magnitude and hours to meet the given total daily requirement, was further investigated to obtain insights into the characteristics of flexible load for demand response. The average PEV flexible load by hour of day and month of year varied little between the low and mid-range RPS targets, but a distinct pattern emerged at high RPS targets for AllCA. At these higher RPS targets, the model found that the optimal time for PEV flexible load was mid-day, roughly between 10am and 4pm PST, especially during sunny spring and summer days. This suggests that flexible PEV load strongly enables solar PV production and minimizes any associated overgeneration. The NREL Renewable Electricity Futures Study similarly observed that charging the flexible portion of the PEV load during periods when curtailment occurs (generally during daytime hours, notably in the spring, when wind and solar production was high) was optimal; energy storage 
served a similar role by shifting load to meet the growing solar PV generation levels [3]. The SWITCH model also observed these same flexibility benefits from "movable" PEV load (part of a larger group of demand response options), which served a similar role as storage by shifting load to facilitate a larger penetration of solar PV generation [23].

The $80 \%$ and $100 \%$ RPS time-based PEV flexible load results were then compared with the Pacific Gas and Electric Company (PG\&E) residential time-of-use (TOU) rate structure, which is a voluntary time-based electricity pricing program that charges pre-set rates for pre-defined onpeak, part-peak, and off-peak load periods. PG\&E is a large utility in northern and central California, which falls within the AllCA region evaluated in this study. As shown in Figure 7 , there was significant alignment between the peak and part-peak TOU critical price-incentivized periods (red solid lines and white dashed lines, respectively) with the optimal PEV flexible loads. These TOU price signals would disincentivize any PEV flexible load during these hours. If the optimal (from a whole-system perspective) flexible load is desired, then demand response programs, which include price-based and incentive-based mechanisms (such as TOU) to curtail and/or shift demand, will likely need to adjust their existing structures to encourage the ideal load timing and magnitude response in future highly renewable systems. The ideal times for TOU off-peak load price periods, in order to incentivize ideal PEV charging, will be times with low or negative net load (load minus variable generation). Conversely, ideal times for TOU peak periods will be periods with high net load.

The reduction in total renewable overgeneration due to PEV was further analyzed by the time of day and year in which these reductions were observed. Figure 8 shows the difference plots (PEV minus noPEV) for AllCA at $80 \%$ and $100 \%$ RPS targets. Most renewable overgeneration occurred during spring mid-day for solar and spring early- and late-day for wind. The reduction in renewable overgeneration due to PEV (negative values in difference plots) was dispersed, but was most noticeable for solar in mid-to-late afternoon spring days and for wind in late-night spring days at an $80 \%$ RPS target. Savings were even more dispersed at a 100\% RPS target. These renewable overgeneration timing trends may be an important consideration if this overgeneration energy is to be used for other applications (e.g., district heating, irrigation pumps, or water desalination/purification). Future work should include these additional value streams.

\subsection{Pathways to $100 \%$ RPS for the contiguous US}

The cost and renewable overgeneration results of the six scenarios for transitioning to a fully renewable US system (independent FERC regions, aggregated FERC regions, and aggregated FERC regions with pathways buildout, each with and without PEV load) are shown in Figure 9. Like the AllCA case in Section 4.1.2, the total system costs roughly doubled from $80 \%$ to $100 \%$ RPS targets in all three sets of US scenarios. For comparison, renewable energy sources provided on average about $13 \%$ of the US electricity generation in 2014 .

These results highlight the benefits of aggregation and PEV load flexibility. Aggregation (third and fourth bars in each RPS target set) yielded lower cost and renewable overgeneration, relative to the independent region cases (first and second bars). These aggregation benefits were more pronounced at higher RPS targets; for example, total costs were reduced by about $50 \%$ and $42 \%$ 
at the $80 \%$ and $100 \%$ RPS targets, respectively, for the aggregate US system versus independent regions. These scenarios included storage and overgeneration, and similar cost savings were observed for cases both with and without PEV load. Additionally, the incremental buildout of storage and transmission was significant at $\geq 60 \%$ RPS targets, with much less storage and total cost in the interconnected system. This indicates that, as the system becomes more renewable, building transmission to access a wider diversity of renewable resources and load is a more economical option than building more storage to access only local resources.

The benefit of PEV load flexibility was the same as that observed for the AllCA case in Section 4.1.2, both for the independent and aggregated regions cases. The additional flexible PEV load resulted in greater system utilization and lower renewable overgeneration, especially for high RPS targets. Additionally, for all RPS targets within each of the three sets of scenarios, the PEV cases generally had larger total transmission costs, larger total wind and solar costs, and smaller relative storage costs compared to the corresponding non-PEV cases. This suggests that the presence of flexible load - or demand response in a broader sense - shifts the system's economic preference from a more regional basis with greater shares of relative storage to a more aggregated, interconnected system with more dispersed renewables and less relative local storage.

The results for the pathways buildouts (fifth and sixth bars) only differed from the non-pathways aggregate cases in their renewable overgeneration values. The pathways buildouts had larger renewable overgeneration values at high RPS targets due to over-building and over-using wind and solar units, as summarized in Table 2. The least-cost wind and solar site developments at low RPS targets in the pathways buildouts were not optimal for matching load when the system lacked flexible natural gas generators at high RPS targets. Forcing the system to maintain these lower-RPS-target wind and solar sites at higher RPS targets resulted in even greater excess total capacity and production.

On a regional level, significant increases in ISONE wind and AllCA, ERCOT, and SPP largescale PV were observed with the pathways buildout (Table 2), with notable reductions in largescale PV in the NW and SW regions. Additionally, the larger overall wind and solar capacities resulted in more overall storage capacity, as reflected in the larger total battery storage capacity. This was especially true in the ERCOT region, where significantly more storage was built to help accommodate the massive increase in large-scale solar PV.

Since the $100 \%$ RPS pathways buildout had comparatively more renewable overgeneration and storage capacity, it required less transmission capacity to meet the region's flexibility needs, as reflected by the overall smaller total transmission flows compared to the non-pathways case. However, the dominant net transmission inter-regional flow directions (Figure 10) were the same as with the non-pathways buildout. For instance, the NW region was still a net exporter of electricity in the pathways buildout, but - as indicated by the relative increase in electricity imported and decrease in the amount exported (Table 2) - its net export magnitude was smaller in the pathways buildout case. The MISO region, on the other hand, was a comparatively greater net exporter in the pathways buildout case. 
Table 3 summarizes the regional and overall ("Total") achieved RPS targets for the interconnected pathways runs without PEV load (i.e., last bar in each RPS set in Figure 9). Achieved RPS targets were based on the delivered (i.e., non-overproduced portion) energy from renewable generators. As noted in Chapter 5 of [17], the interconnected cases resulted in a surprisingly large range of achieved RPS targets among the constituent regions for all RPS targets below 100\%. For the 100\% RPS target, all regions achieved 100\% RPS since only generation from renewable sources was allowed.

The regions with sub-target RPS values were along the high-load East Coast (ISONE, NYISO, PJM, SE) and in ERCOT, while those with above-target-levels of renewable production were in the western half of the US; NW was dominated by hydro and wind, MISO and SPP by wind, AllCA by all renewables, and SW by wind and solar. As a result, transmission net flows and the corresponding additional new transmission capacity generally followed a dominant west-to-east orientation. As shown in Figure 10 for the 100\% RPS target without PEV load, the largest new transmission capacity was found along a northern west-to-east path of NW-MISO-PJM and a southern west-to-east path of SW-SPP-SE. This west-to-east new transmission capacity requirement is similar to the results in the NREL Renewable Futures Study for the $80 \%$ RE-ITI scenario [3], which found the greatest new transmission capacity buildout in the west-east orientation from the southwest to central-southwest (crossing the three interconnection boundaries) and from the Great Plains eastward.

As an additional result of the pathways buildout of an aggregated US system without PEV load, the emissions from natural gas and coal generators are shown in Figure 11 for each RPS target. Similar values and trends were observed for the equivalent cases with PEV load. Total annual emissions for $\mathrm{CO}_{2}, \mathrm{SO}_{2}, \mathrm{NO}_{x}$, and $\mathrm{PM}_{10}$ for $20 \%$ to $100 \%$ RPS targets in US (both with and without PEV load) decreased linearly for each successive RPS target; no emissions were produced at $100 \%$ RPS. The largest total savings were from $\mathrm{CO}_{2}$, with a reduction of about 350 million metric tons/year with each successive RPS target. $\mathrm{NO}_{\mathrm{x}}$ had a reduction of about 60 thousand metric tons/year, $\mathrm{PM}_{10}$ a reduction of about 17 thousand metric tons/year, and $\mathrm{SO}_{2}$ a reduction of about 600 metric tons/year, for each successive RPS target.

The avoided health care and climate damage costs - often referred to as "social costs" - from these reductions in fossil-based emissions provide a useful comparison to the total system cost results in Figure 9. For the US system with aggregated (interconnected) regions, all scenarios show a moderate increase in total system cost from about 250 billion $2006 \mathrm{USD} / \mathrm{year}$ to about 330 billion $2006 \mathrm{USD} /$ year from the $20 \%$ to $80 \%$ RPS target. The $\mathrm{CO}_{2}$ emission reductions between these same RPS targets is roughly 1 billion metric tons/year (Figure 11). Based on a recently updated social cost of carbon (SCC) value [64], this $\mathrm{CO}_{2}$ reduction alone equates to an avoided health and environmental costs of about 200 billion 2006USD/year. A similar cost savings of 190 billion 2006USD/year is found between the same 20\% and $80 \%$ RPS targets if $\mathrm{CO}_{2}$ plus a broader set of pollutants are considered, assuming the median US-based coal and natural gas generator Social Cost of Atmospheric Release (SCAR) values with a 3\% discount rate [65]. If PEV load is included, an additional 50 billion 2006USD/year cost savings are realized, using the median SCAR values with a 3\% discount rate for gasoline and PEV load equivalency of 13.7 billion gallons (see Section 4.1.2). These results reveal that, based on either the SCC or SCAR cost metrics, the avoided social costs due to the reduction in fossil-based 
emissions significantly outweighs the required system cost of about 80 billion 2006USD/year to transition from a $20 \%$ to $80 \%$ RPS interconnected US grid. However, beyond this RPS target or without regional aggregation, system costs outweigh the social benefits.

\subsection{Sensitivity analyses}

Various sensitivity scenarios were investigated for both a single region (AllCA) and a fully interconnected US system. These scenarios independently considered the impact of including existing capacity levels, larger load requirements, lower residential PV costs, an alternative reserve requirement model formulation, environmental externalities costs, and natural gas price uncertainties. A detailed description of all scenarios and results are discussed in Appendix A.

Results revealed that the model outputs have low sensitivity to the various input parameters and formulations tested. Including existing generator and storage capacities resulted in excess capacity and increased renewable overgeneration. Adjusting fossil-based generator costs, while keeping all else unchanged, had nearly no impact on system development but did affect the total system cost due to the relative increase/decrease in fossil-based cost inputs. Implementing a larger load requirement yielded a disproportionately larger total cost due to increased capacity and production values. Accounting for additional residential PV benefits resulted in a small increase in installed residential PV capacity. Implementing a different reserve requirement model yielded nearly identical results and served as a validation of the reserve requirement model in POWER.

\section{Summary and conclusions}

A large-scale linear programming model called POWER was built to deterministically find the least-cost portfolio of generators (baseload, dispatchable, and variable), storage, and transmission that meet the electric load and reserve requirements in each hour while attaining a given RPS target. The model was validated against three existing power system planning models of different spatial extents across the contiguous US. Sensitivity runs of a modified full-California FERC region named "AllCA" and also the entire contiguous US revealed that the model outputs have low sensitivity to the various parameters and formulations tested.

POWER was applied to a number of model scenarios with RPS targets between $20 \%$ and $100 \%$ for the AllCA region, western US (WECC), and contiguous US to provide a comparison of pathways to a fully renewable electricity system and to demonstrate the individual and combined effects of four flexibility mechanisms: (1) geographic aggregation, (2) renewable overgeneration, (3) storage, and (4) new primarily flexible load from electric vehicle charging.

Of the flexibility mechanisms considered, geographic aggregation had the greatest total system cost benefit, with total system cost savings on the order of $5-10 \%$ for the interconnected WECC region. In these interconnected scenarios, inter-region transmission costs were generally less than about $5 \%$ of the total cost. Additionally, the contribution of each region to the aggregate RPS 
varied widely due to regional differences in renewable resource availability and economic attractiveness, highlighting the need for region-and-resource-specific RPS targets.

Electric vehicle charging, which adds primarily flexible new load to the system, always resulted in a larger total system cost but smaller total system levelized cost. This result was even more pronounced at higher RPS targets and highlights the need for demand-side flexibility as the penetration of renewables increases in order to increase system utilization and decrease the system levelized cost. However, based on a comparison of "optimal" PEV charging times with an existing TOU rate structure, certain existing demand response price structures must be revised to encourage ideal flexible load in highly renewable systems.

For the contiguous US, all scenarios with interconnected FERC regions showed a moderate increase in total system cost from about 250 billion 2006USD/year to about 330 billion 2006USD/year for scenarios with RPS targets increasing from $20 \%$ to $80 \%$ (a difference of about 80 billion 2006USD/year). For independent, non-interconnected FERC regions that comprised the contiguous US, the corresponding increase was significantly larger with a total cost of about 250 billion $2006 \mathrm{USD} /$ year for the 20\% RPS target and 670 billion $2006 \mathrm{USD} /$ year for the $80 \%$ RPS target (a difference of about 420 billion 2006USD/year). These increases can be compared to the health and climate cost savings of avoided fossil-based emissions from the $20 \%$ to $80 \%$ RPS target. The avoided cost from $\mathrm{CO}_{2}$ emission reductions alone between these two RPS targets equates to about 200 billion 2006USD/year savings. A similar cost savings is found if $\mathrm{CO}_{2}$ plus a broader set of coal and natural gas pollutants are considered. These cost savings significantly outweigh the required interconnected US system costs of about 80 billion 2006 USD/year from a $20 \%$ to $80 \%$ RPS target. However, beyond this RPS target or without regional aggregation, system costs outweigh the social benefits.

Fully renewable (100\% RPS) systems for AllCA and the full US were found to be feasible with the given model assumptions, but with at least twice the cost and three times the renewable overgeneration of the $80 \%$ RPS target. The full US 100\% RPS target costs were about 720 billion 2006USD/year with interconnected FERC regions and 1,230 billion 2006USD/year with independent, non-interconnected FERC regions. A comparison of various transitions to a fully renewable US system again showed that costs are larger without aggregation. In these US scenarios, which included storage and overgeneration, the benefits of aggregation are amplified at larger RPS targets; this was true for cases both with and without PEV load. Total costs are reduced by about $50 \%$ and $42 \%$ at the $80 \%$ and $100 \%$ RPS targets, respectively, for the aggregate US system versus independent regions. Total costs were roughly the same but overgeneration was up to about $15 \%$ greater if the system assumed an iterative, pathways buildout to a fully renewable system.

This work contributes to the growing field of power system planning modeling and analyses of highly renewable electricity systems. The findings presented here reflect feasible scenarios for a simplified US electricity system from a planning perspective only, which ignores stability and reliability issues on sub-hourly timescales, such as frequency and voltage control. This study also ignores many social, environmental, and political barriers, which may slow or prevent actual implementation. Future work should focus on defining the optimal role of demand-side measures in aiding the transition to a fully renewable electricity system. 


\section{Acknowledgements}

The results presented here largely draw from the lead author's dissertation [17]. BAF gratefully acknowledges financial support from a National Defense Science and Engineering Graduate (NDSEG) fellowship, a National Science Foundation (NSF) graduate fellowship, and a Stanford University Charles H. Leavell Graduate Student Fellowship; SB from O. and H. Stöcker and M. and H. Puschmann; and GBA from DONG Energy and Innovation Fund Denmark (IFD).

\section{Appendix A. Supplementary data}

Supplementary data associated with this article can be found in the online version.

\section{References}

[1] C. Budischak, D. Sewell, H. Thomson, L. Mach, D.E. Veron, W. Kempton, Cost-minimized combinations of wind power, solar power and electrochemical storage, powering the grid up to $99.9 \%$ of the time, J. Power Sources. 225 (2013) 60-74. doi:http://dx.doi.org/10.1016/j.jpowsour.2012.09.054.

[2] J. Nelson, J. Johnston, A. Mileva, M. Fripp, I. Hoffman, A. Petros-Good, et al., High-resolution modeling of the western North American power system demonstrates low-cost and low-carbon futures, Energy Policy. 43 (2012) 436-447. doi:10.1016/j.enpol.2012.01.031.

[3] National Renewable Energy Laboratory, Renewable Electricity Futures Study, Golden, CO, US, 2012. http://www.nrel.gov/analysis/re_futures/.

[4] K. Schaber, F. Steinke, T. Hamacher, Transmission grid extensions for the integration of variable renewable energies in Europe: Who benefits where?, Energy Policy. 43 (2012) 123-135. doi:http://dx.doi.org/10.1016/j.enpol.2011.12.040.

[5] G. Czisch, G. Giebel, Realisable Scenarios for a Future Electricity Supply based $100 \%$ on Renewable Energies, in: Risø Int. Energy Conf., Risø,DK, 2007. http://130.226.56.153/rispubl/reports/ris-r-1608_186195.pdf.

[6] EnerNex Corporation, Eastern Wind Integration and Transmission Study, Knoxville, Tennessee, 2010. http://www.nrel.gov/docs/fy11osti/47078.pdf.

[7] GE Energy, Western Wind and Solar Integration Study, Schenectady, New York, 2010. http://www.nrel.gov/docs/fy10osti/47434.pdf.

[8] N.W. Miller, M. Shao, S. Pajic, R. D'Aquila, K. Clark, Western Wind and Solar Integration Study Phase 3 Frequency Response and Transient Stability, National Renewable Energy Laboratory NREL/SR-5D0062906, Golden, CO, US, 2014.

[9] Energy and Environmental Economics, Investigating a Higher Renewables Portfolio Standard in California, San Francisco, CA, 2014. https://ethree.com/documents/E3_Final_RPS_Report_2014_01_06_with_appendices.pdf.

[10] B. Elliston, M. Diesendorf, I. MacGill, Simulations of scenarios with $100 \%$ renewable electricity in the Australian National Electricity Market, Energy Policy. 45 (2012) 606-613. doi:http://dx.doi.org/10.1016/j.enpol.2012.03.011.

[11] C.J. Barnhart, M. Dale, A.R. Brandt, S.M. Benson, The energetic implications of curtailing versus storing solar- and wind-generated electricity, Energy Environ. Sci. 6 (2013) 2804-2810.

[12] A. Tuohy, M. O'Malley, Pumped storage in systems with very high wind penetration, Energy Policy. 39 (2011) 1965-1974. doi:10.1016/j.enpol.2011.01.026. 
[13] J. King, B. Kirby, M. Milligan, S. Beuning, Flexibility Reserve Reductions from an Energy Imbalance Market with High Levels of Wind Energy in the Western Interconnection, National Renewable Energy Laboratory NREL/TP-5500-52330, Golden, CO, US, 2011.

[14] P. Denholm, M. Hand, Grid flexibility and storage required to achieve very high penetration of variable renewable electricity, Energy Policy. 39 (2011) 1817-1830.

http://www.sciencedirect.com/science/article/pii/S0301421511000292.

[15] P. Denholm, J. Jorgenson, M. Hummon, D. Palchak, B. Kirby, O. Ma, et al., The Impact of Wind and Solar on the Value of Energy Storage, National Renewable Energy Laboratory, NREL/TP-6A20-60568, Golden, CO, US, 2013.

[16] B.A. Corcoran (Frew), N. Jenkins, M.Z. Jacobson, Effects of aggregating electric load in the United States, Energy Policy. 46 (2012) 399-416. doi:10.1016/j.enpol.2012.03.079.

[17] B.A. Frew, Optimizing the Integration of Renewable Energy in the United States, Stanford University, 2014. http://purl.stanford.edu/hr320qr0229.

[18] W. Short, P. Sullivan, T. Mai, M. Mowers, C. Uriarte, N. Blair, et al., Regional Energy Deployment System (ReEDS), National Renewable Energy Laboratory, NREL/TP-6A20-46534, Golden, CO, US, 2011. http://www.nrel.gov/analysis/reeds/pdfs/reeds_documentation.pdf.

[19] U.S. Energy Information Administration, The Electricity Market Module of the National Energy Modeling System: Model Documentation Report, DOE/EIA-M068(2011), 2011.

ftp://ftp.eia.doe.gov/modeldoc/m068(2011).pdf.

[20] Electric Power Research Institute, PRISM 2.0: Regional Energy and Economic Model Development and Initial Application, Palo Alto, CA, 2013. http://www.epri.com/abstracts/Pages/ProductAbstract.aspx?ProductId=000000003002000128.

[21] G.J. Blanford, J.H. Merrick, D. Young, A Clean Energy Standard Analysis with the US-REGEN Model, Energy J. 35 (2014). doi:http://dx.doi.org/10.5547/01956574.35.SI1.8.

[22] M. Fripp, Switch: A Planning Tool for Power Systems with Large Shares of Intermittent Renewable Energy, Environ. Sci. Technol. 46 (2012) 6371-6378. doi:10.1021/es204645c.

[23] J.H. Nelson, Scenarios for Deep Carbon Emission Reductions from Electricity by 2050 in Western North America Using the SWITCH Electric Power Sector Planning Model, University of California, Berkeley, 2013.

[24] R. Fourer, D.M. Gay, B.W. Kernighan, AMPL: A Modeling Language for Mathematical Programming, Second, Brooks/Cole Cengage Learning, Belmont, CA, 2003.

[25] IBM, IBM ILOG AMPL Version 12.2 User's Guide, 2010. http://ampl.com/BOOKLETS/amplcplex122userguide.pdf.

[26] National Renewable Energy Laboratory, Wind Integration Datasets - Western Wind Dataset, (2010). http://www.nrel.gov/wind/integrationdatasets/western/methodology.html.

[27] National Renewable Energy Laboratory, Wind Integration Datasets - Eastern Wind Dataset, (2010). http://www.nrel.gov/wind/integrationdatasets/eastern/methodology.html.

[28] M.J. Dvorak, B.A. Corcoran (Frew), J.E. Ten Hoeve, N.G. McIntyre, M.Z. Jacobson, US East Coast offshore wind energy resources and their relationship to peak-time electricity demand, Wind Energy. 16 (2013) 977-997. doi:10.1002/we.1524.

[29] S. Becker, B.A. Frew, G.B. Andresen, T. Zeyer, S. Schramm, M. Greiner, et al., Features of a fully renewable US electricity system: Optimized mixes of wind and solar PV and transmission grid extensions, Energy. 72 (2014) 443-458. doi:10.1016/j.energy.2014.05.067.

[30] Black \& Veatch, Cost and Performance Data for Power Generation Technologies, 2012. http://bv.com/docs/reports-studies/nrel-cost-report.pdf.

[31] National Renewable Energy Laboratory, National Solar Radiation Database: 1991-2010 Update, (2012). http://www1.ncdc.noaa.gov/pub/data/nsrdb-solar/.

[32] Federal Energy Regulatory Commission, Form No. 714 - Annual Electric Balancing Authority Area and Planning Area Report, (2010). http://www.ferc.gov/docs-filing/forms/form-714/view-soft.asp.

[33] D.G. Hall, K.S. Reeves, J. Brizzee, R.D. Lee, G.R. Carroll, G.L. Sommers, Feasibility Assessment of the Water Energy Resources of the United States for New Low Power and Small Hydro Classes of Hydroelectric Plants, Idaho National Laboratory DOE-ID-11263, Idaho Falls, ID, US, 2006. http://hydropower.inl.gov/resourceassessment/pdfs/main_report_appendix_a_final.pdf.

[34] J.W. Tester B. Anderson, A. Batchelor, D. Blackwell, R. DiPippo, E. Drake, J. Garnish, B. Livesay, M. C. Moore, K. Nichols, S. Petty, N. Toksoz, R. Veatch, C. Augustine, R. Baria, E. Murphy, P. Negraru, and M. Richards, J.W. Tester, B. Anderson, A. Batchelor, D. Blackwell, R. DiPippo, et al., The future of geothermal 
energy: Impact of enhanced geothermal systems (EGS) on the United States in the 21st century, Massachusetts Institute of Technology, DOE Contract DE-AC07-05ID14517, 2006.

[35] C.F. Williams, M.J. Reed, R.H. Mariner, J. DeAngelo, S.P. Galanis Jr., C.F. Williams M. J. Reed, R. H. Mariner, J. DeAngelo, and S. P. Galanis, Jr., Assessment of Moderate- and High-Temperature Geothermal Resources of the United States, USGS, 2008.

[36] Electric Power Research Institute, Transportation Statistics Analysis for Electric Transportation, Palo Alto, CA, 2011. http://www.epri.com/abstracts/Pages/ProductAbstract.aspx?ProductId=000000000001021848.

[37] Rextag Strategies, U. S. Electric Transmission and Power Plants Digital GIS Data, (2008).

[38] L. Weiss, S. Spiewak, The Wheeling and Transmission Manual, 3rd ed., The Fairmont Press, Inc., Lilburn, 1999.

[39] D.F. Shankle, Incremental Voltage Uprating of Transmission Lines, IEEE Trans. Power Appar. Syst. PAS90 (1971) 1791-1795.

[40] T. Mai, C. Barrows, A. Lopez, E. Hale, M. Dyson, K. Eurek, Implications of Model Structure and Detail for Utility Planning: Scenario Case Studies Using the Resource Planning Model, National Renewable Energy Laboratory, NREL/TP-6A20-63972, Golden, CO, US, 2015.

[41] R. Baldick, Wind and Energy Markets: A Case Study of Texas, IEEE Syst. J. 6 (2012) 27-34.

[42] M. Sahraei-Ardakani, S. Blumsack, A. Kleit, Distributional impacts of state-level energy efficiency policies in regional electricity markets, Energy Policy. 49 (2012) 365-372.

[43] M. Sahraei-Ardakani, S. Blumsack, A. Kleit, Estimating zonal electricity supply curves in transmissionconstrained electricity markets, Energy. 80 (2015) 10-19.

[44] M. Contestabile, G. Offer, R. Slade, F. Jaeger, M. Thoenees, Battery electric vehicles, hydrogen fuel cells and biofuels. Which will be the winner?, Energy Environ. Sci. 4 (2011) 3754-3772.

[45] E.K. Hart, M.Z. Jacobson, A Monte Carlo Approach to Generator Portfolio Planning and Carbon Emissions Assessments of Systems with Large Penetrations of Variable Renewables, Renewable Energy, 2011. doi:10.1016/j.renene.2011.01.015.

[46] A.H. van der Weijde, B.F. Hobbs, Planning electricity transmission to accommodate renewables: Using twostage programming to evaluate flexibility and the cost of disregarding uncertainty, EPRG Working Paper 1102, Cambridge Working Paper in Economics 1113, 2011. http://www.eprg.group.cam.ac.uk/wpcontent/uploads/2011/01/Binder11.pdf.

[47] A. MacDonald, C. Clack, A. Alexander, A. Dunbar, Y. Xie, J. Wilczak, Low Cost and Low Carbon Wind and Solar Energy Systems: Feasible with Large Geographic Size, in: NOAA Sustain. Energy Atmos. Sci. Semin., 2014. http://www.esrl.noaa.gov/events/seminars/seas/2014/pdf/seas-052714-slides.pdf.

[48] L. Bird, J. Cochran, X. Wang, Wind and Solar Energy Curtailment: Experience and Practices in the United States, National Renewable Energy Laboratory, NREL/TP-6A20-60983, Golden, CO, US, 2014. http://www.nrel.gov/docs/fy14osti/60983.pdf.

[49] DSIRE, Database of State Incentives for Renewables and Efficiency RPS Data Spreadsheet, (2014).

[50] T.K. Kristoffersen, K. Capion, P. Meibom, Optimal charging of electric drive vehicles in a market environment, Appl. Energy. 88 (2011) 1940-1948. doi:http://dx.doi.org/10.1016/j.apenergy.2010.12.015.

[51] D.B. Richardson, Electric vehicles and the electric grid: A review of modeling approaches, Impacts, and renewable energy integration, Renew. Sustain. Energy Rev. 19 (2013) 247-254. doi:http://dx.doi.org/10.1016/j.rser.2012.11.042.

[52] D. Dallinger, M. Wietschel, Grid integration of intermittent renewable energy sources using priceresponsive plug-in electric vehicles, Renew. Sustain. Energy Rev. 16 (2012) 3370-3382. doi:http://dx.doi.org/10.1016/j.rser.2012.02.019.

[53] W. Kempton, S. Letendre, Electric vehicles as a new power source for electric utilities, Transp. Res. Part D. 2 (1997) 157-175.

[54] S.W. Hadley, Impact of plug-in hybrid vehicles on the electric grid, Oak Ridge National Laboratory, Oak Ridge, TN, US, ORNL/TM-2006/554, 2006. http://web.ornl.gov/info/ornlreview/v40_2_07/2007_plugin_paper.pdf.

[55] K. Clement-Nyns, E. Haesen, J. Driesen, The Impact of Charging Plug-In Hybrid Electric Vehicles on a Residential Distribution Grid, IEEE Trans. Power Syst. 25 (2010) 371-380. doi:10.1109/TPWRS.2009.2036481.

[56] R.C. Green, L. Wang, M. Alam, The impact of plug-in hybrid electric vehicles on distribution networks: A review and outlook, Renew. Sustain. Energy Rev. 15 (2011) 544-553. doi:http://dx.doi.org/10.1016/j.rser.2010.08.015.

[57] M.Z. Jacobson, Review of solutions to global warming, air pollution, and energy security, Energy Environ. 
Sci. 2 (2009) 148-173. http://dx.doi.org/10.1039/B809990C.

[58] P.M. Sotkiewicz, Demand Response Opportunities Facilitated by Smart Grid Technologies in PJM, in: Optim. Distrib. Syst. High Penetration Renewables Smart Grid Work., TomKat Center for Sustainable Energy, Stanford University, Stanford, CA, 2012.

http://tomkat.stanford.edu/docs/Paul_Sotkiewicz_workshop2012.pdf.

[59] Federal Energy Regulatory Commission, A National Assessment of Demand Response Potential, Washington, DC, 2009. http://www.ferc.gov/legal/staff-reports/06-09-demand-response.pdf.

[60] M. Milligan, B. Kirby, Utilizing Load Response for Wind and Solar Integration and Power System Reliability, WindPower. NREL/CP-55 (2010). http://www.nrel.gov/docs/fy10osti/48247.pdf.

[61] North American Electric Reliability Corporation, Accommodating High Levels of Variable Generation, 2009. http://www.nerc.com/files/IVGTF_Report_041609.pdf.

[62] C. De Jonghe, B.F. Hobbs, R. Belmans, Optimal Generation Mix With Short-Term Demand Response and Wind Penetration, IEEE Trans. Power Syst. 27 (2012) 830-839. doi:10.1109/TPWRS.2011.2174257.

[63] J.H. Williams, A. DeBenedictis, R. Ghanadan, A. Mahone, J. Moore, W.R. Morrow III, et al., The technology path to deep greenhouse gas emissions cuts by 2050: the pivotal role of electricity, Science (80). 335 (2012) 53-59. doi:10.1126/science.1208365.

[64] F.C. Moore, D.B. Diaz, Temperature impacts on economic growth warrant stringent mitigation policy, Nat. Clim. Chang. 5 (2015) 127-131.

[65] D.T. Shindell, The social cost of atmospheric release, Clim. Change. (2015). doi:10.1007/s10584-015-13430 .

Table 1 Percent increase in cost and renewable overgeneration by RPS target due to PEV load for AllCA region. Percent increase is relative to non-PEV case. All percentages are based on total annual system cost, except for overgeneration (far right column), which is based on total annual overgeneration. Note that the table is incomplete due to the lack of feasible solutions.

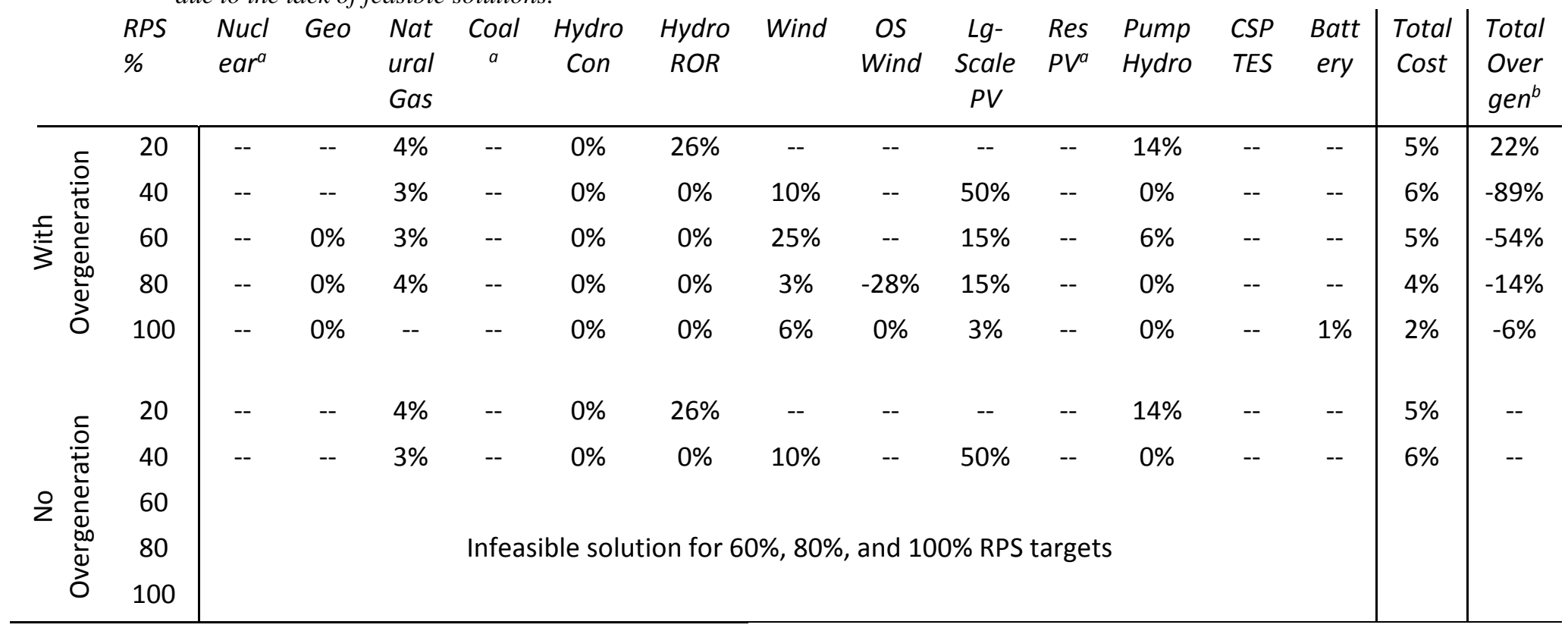

Notes:

Based on AllCA with 8hrs of maximum storage and a representative subset of day (57 days). All costs based on 2006 USD. 
a) No values are given when no capacity was built. No capacity was built for Nuclear, Coal, Residential (rooftop) solar PV, or CSP TES.

b) Model assumes all overgeneration is curtailed from renewable energy (includes all generators except nuclear, natural gas, and coal).

Table 2 Percent increase in installed capacity, transmission flows, or cost with pathways (versus non-pathways) buildout of aggregated (interconnected) US system with a $100 \%$ RPS target without PEV load. All runs used the same 14 representative days with relaxed formulation of CSP TES.

\begin{tabular}{l|ccccccc} 
& Wind & $\begin{array}{c}\text { Offshore } \\
\text { Wind }\end{array}$ & $\begin{array}{c}\text { Lg-Scale } \\
\text { PV }\end{array}$ & $\begin{array}{c}\text { Battery } \\
\text { Storage }\end{array}$ & $\begin{array}{c}\text { Total } \\
\text { Transmit In }\end{array}$ & $\begin{array}{c}\text { Total } \\
\text { Transmit Out }\end{array}$ & $\begin{array}{c}\text { Total Cost } \\
\text { (without Trans) }\end{array}$ \\
\hline AlICA & $1 \%$ & $-2 \%$ & $27 \%$ & $0 \%$ & $-23 \%$ & $-38 \%$ & $7 \%$ \\
ERCOT & $0 \%$ & -- & $1473 \%$ & $561 \%$ & $-33 \%$ & $-18 \%$ & $297 \%$ \\
ISONE & $24 \%$ & $-1 \%$ & $4 \%$ & $11 \%$ & $-19 \%$ & $21 \%$ & $6 \%$ \\
MISO & $9 \%$ & $0 \%$ & $-1 \%$ & $-86 \%$ & $-25 \%$ & $9 \%$ & $4 \%$ \\
NW & $-8 \%$ & $0 \%$ & $-26 \%$ & $0 \%$ & $62 \%$ & $-21 \%$ & $-10 \%$ \\
NYISO & $0 \%$ & $0 \%$ & $-11 \%$ & $0 \%$ & $0 \%$ & $-21 \%$ & $-4 \%$ \\
PJM & $0 \%$ & $0 \%$ & $0 \%$ & $-10 \%$ & $8 \%$ & $5 \%$ & $-2 \%$ \\
SE & $3 \%$ & $0 \%$ & $2 \%$ & $-1 \%$ & $4 \%$ & $15 \%$ & $1 \%$ \\
SPP & $3 \%$ & -- & $23 \%$ & $0 \%$ & $5 \%$ & $5 \%$ & $5 \%$ \\
SW & $4 \%$ & -- & $-29 \%$ & $0 \%$ & $-23 \%$ & $-26 \%$ & $-8 \%$ \\
Total & $\mathbf{4} \%$ & $\mathbf{0 \%}$ & $\mathbf{1} \%$ & $\mathbf{3} \%$ & $-5 \%$ & $-5 \%$ & $\mathbf{2 \%}$ \\
\hline
\end{tabular}

Table 3 RPS targets achieved by each FERC region and total system for pathways buildout of aggregated (interconnected) US system without PEV load. Achieved RPS targets were calculated as the percentage of total load met by the delivered portion of renewable generators. Total values were the system-wide RPS targets. All runs used the same 14 representative days with relaxed formulation of CSP TES.

\begin{tabular}{l|ccccc} 
& \multicolumn{5}{|c}{ RPS Level } \\
& $20 \%$ & $40 \%$ & $60 \%$ & $80 \%$ & $100 \%$ \\
\hline AllCA & $35 \%$ & $55 \%$ & $81 \%$ & $100 \%$ & $100 \%$ \\
ERCOT & $2 \%$ & $5 \%$ & $27 \%$ & $100 \%$ & $100 \%$ \\
ISONE & $5 \%$ & $21 \%$ & $33 \%$ & $59 \%$ & $100 \%$ \\
MISO & $35 \%$ & $72 \%$ & $82 \%$ & $90 \%$ & $100 \%$ \\
NW & $54 \%$ & $76 \%$ & $100 \%$ & $100 \%$ & $100 \%$ \\
NYISO & $0 \%$ & $3 \%$ & $24 \%$ & $85 \%$ & $100 \%$ \\
PJM & $11 \%$ & $29 \%$ & $43 \%$ & $56 \%$ & $100 \%$ \\
SE & $12 \%$ & $22 \%$ & $49 \%$ & $70 \%$ & $100 \%$ \\
SPP & $64 \%$ & $89 \%$ & $100 \%$ & $100 \%$ & $100 \%$ \\
SW & $4 \%$ & $65 \%$ & $97 \%$ & $100 \%$ & $100 \%$ \\
Total & $\mathbf{2 0} \%$ & $\mathbf{4 0} \%$ & $\mathbf{6 0 \%}$ & $\mathbf{8 0} \%$ & $100 \%$ \\
\hline
\end{tabular}




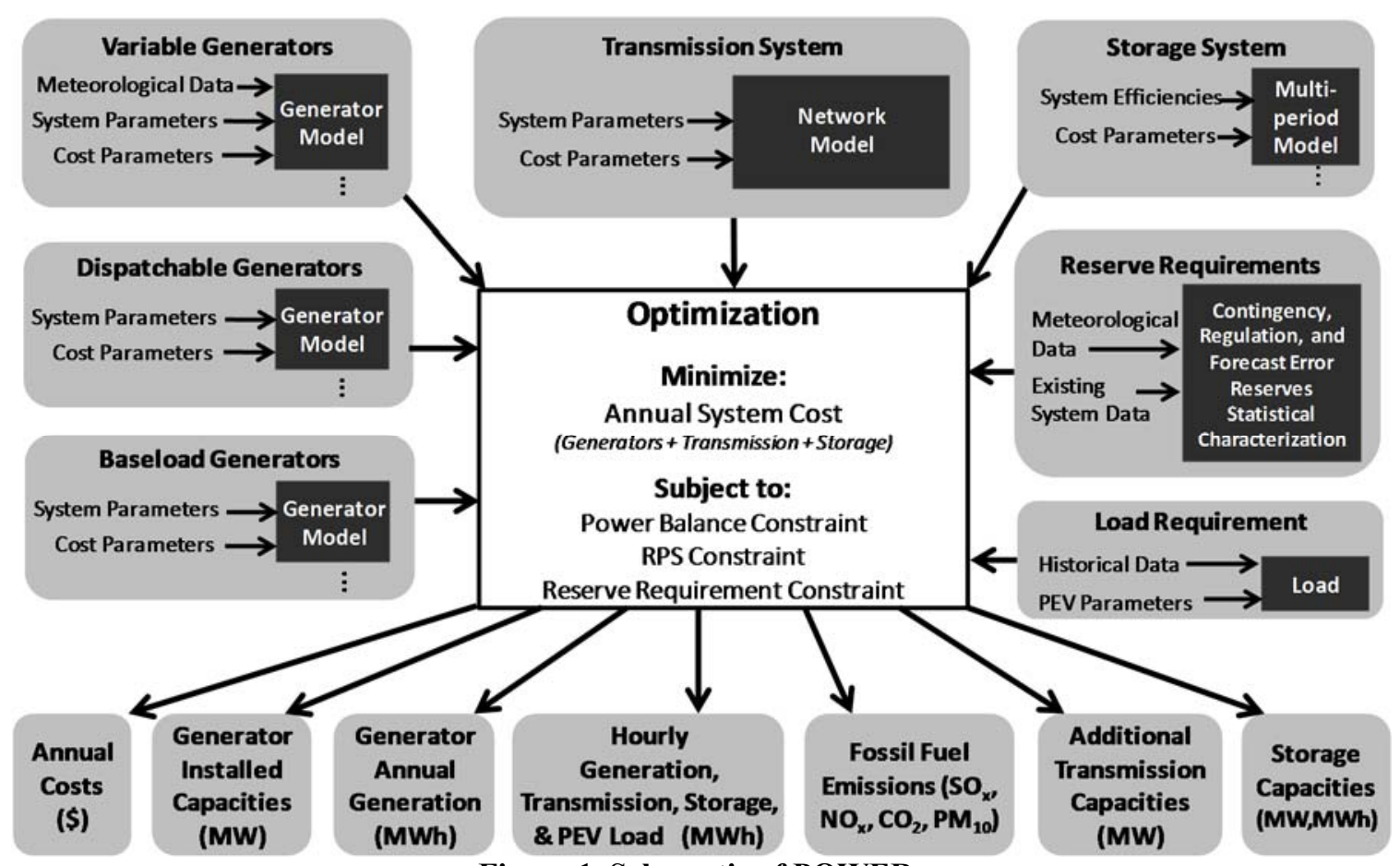

Figure 1 Schematic of POWER.

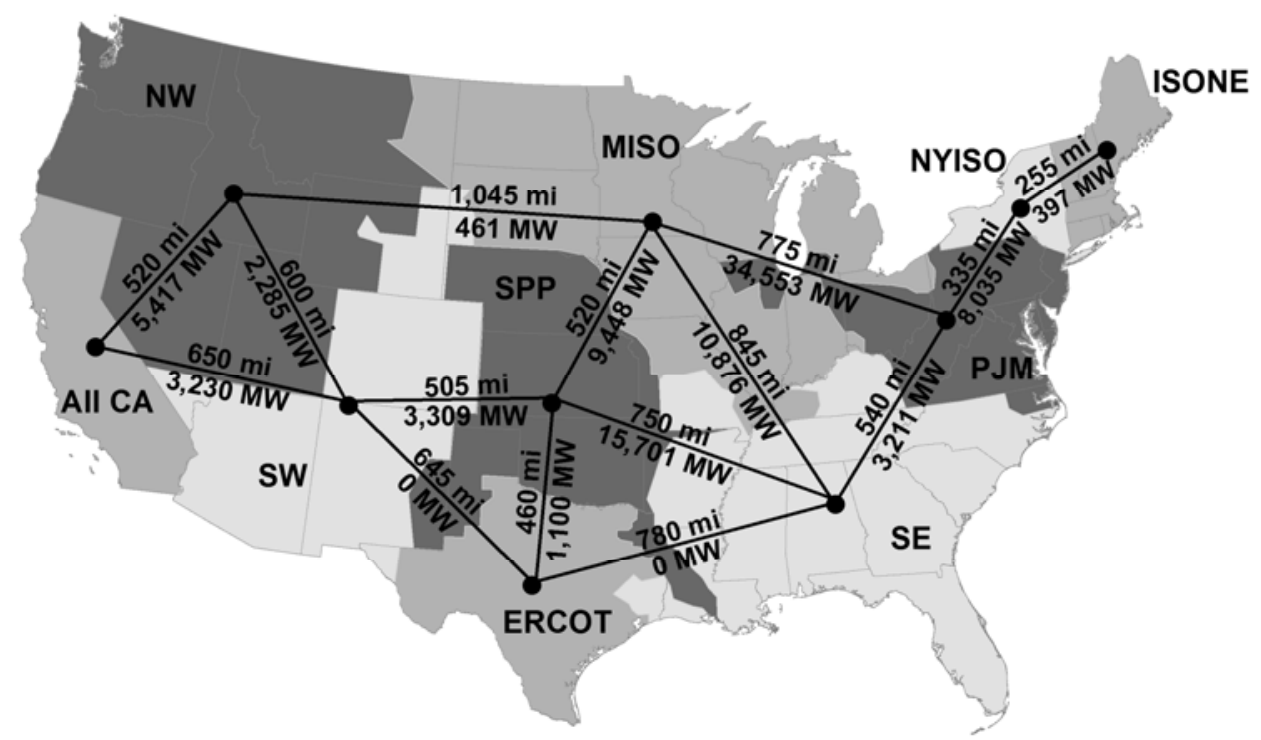

Figure 2 Transmission network topology. Nodes are located at the centroid of each FERC region. Proxy values for inter-region transmission distances (mi) and approximate existing inter-region transmission capacities values (MW) are shown for each segment. Source: [16]. 


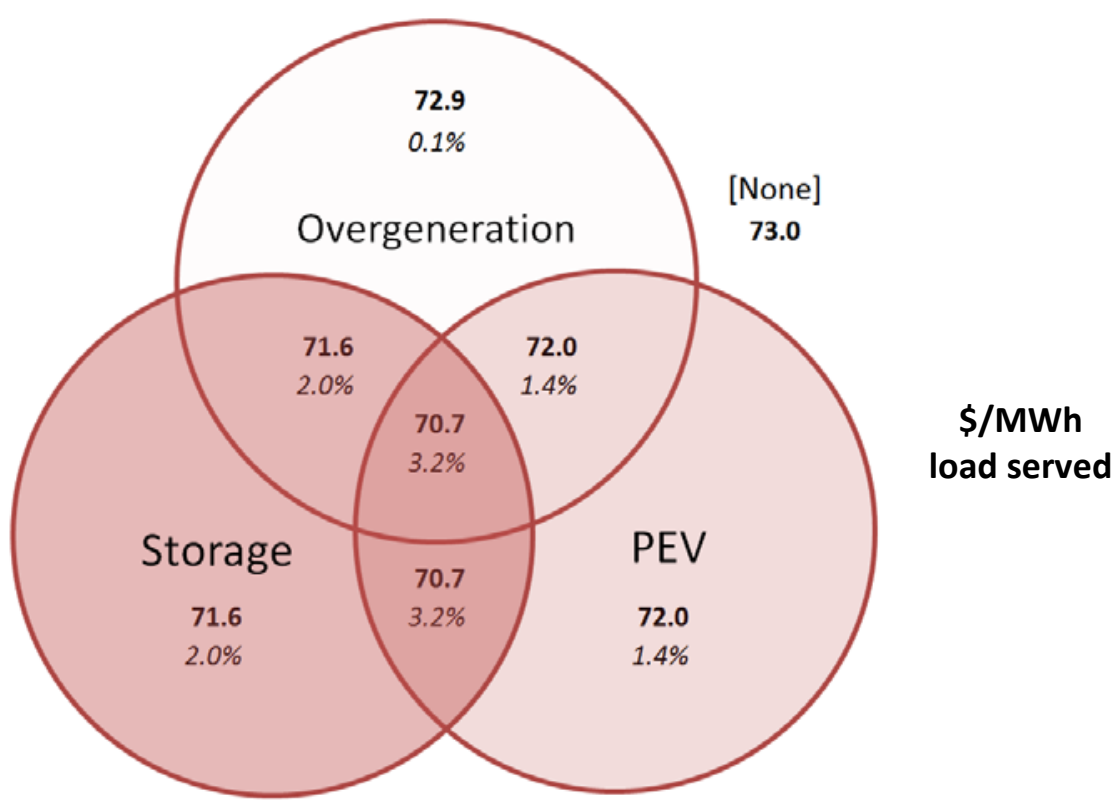

Figure 3 Cost tradeoffs for renewable overgeneration, storage, and PEV load flexibility mechanisms for AllCA region with a 40\% RPS target. Levelized costs (2006USD) are shown in bold, and percent savings relative to no flexibility case ("None") are in italics, for each combination. Shading shows relative savings (darker = greater savings). All values are based on a representative subset of 56 days. Levelized costs are used here to compare the $P E V$ and non-PEV cases on a load-normalized basis.
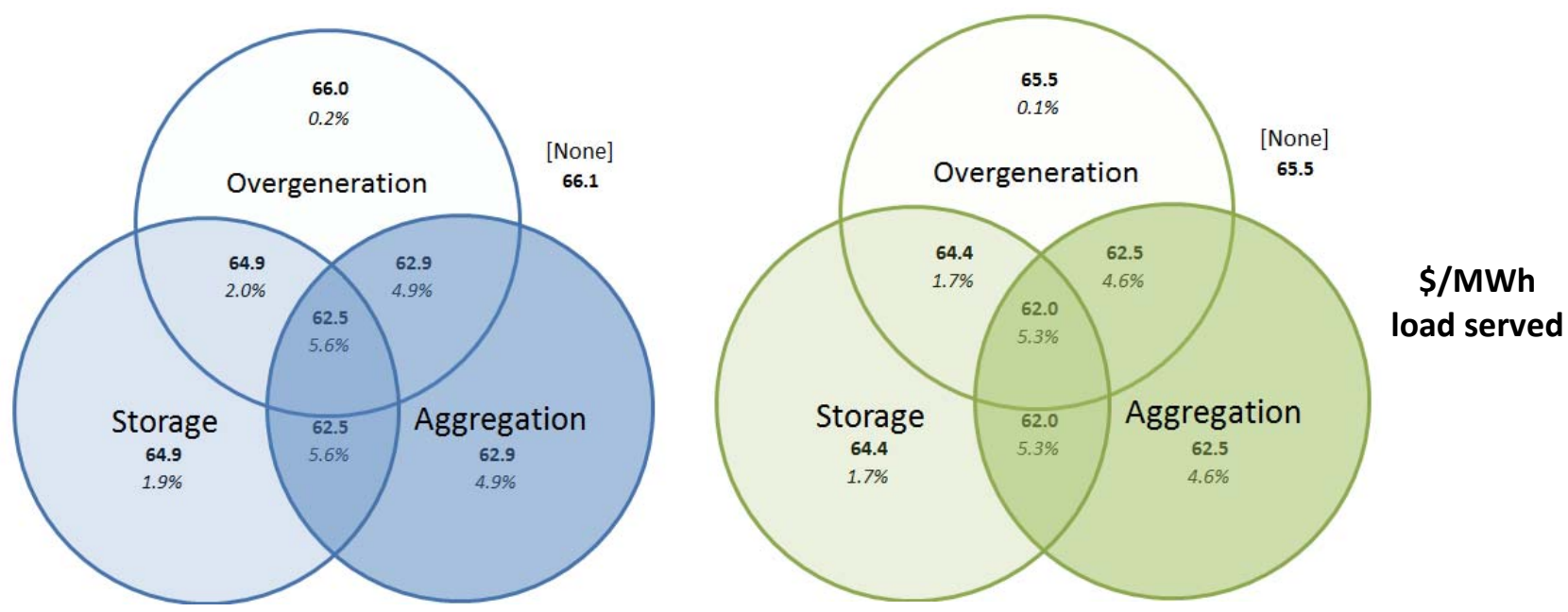

Figure 4 Cost tradeoffs for renewable overgeneration, storage, and aggregation flexibility mechanisms without PEV (left, blue) and with PEV load (right, green) for WECC (AIICA, SW, NW FERC regions) with a 40\% RPS target. Levelized costs (2006USD) are shown in bold, and percent savings relative to no flexibility case ("None") are shown in italics, for each combination. Shading shows relative savings (darker = greater savings). All values are based on a representative subset of 28 days. 


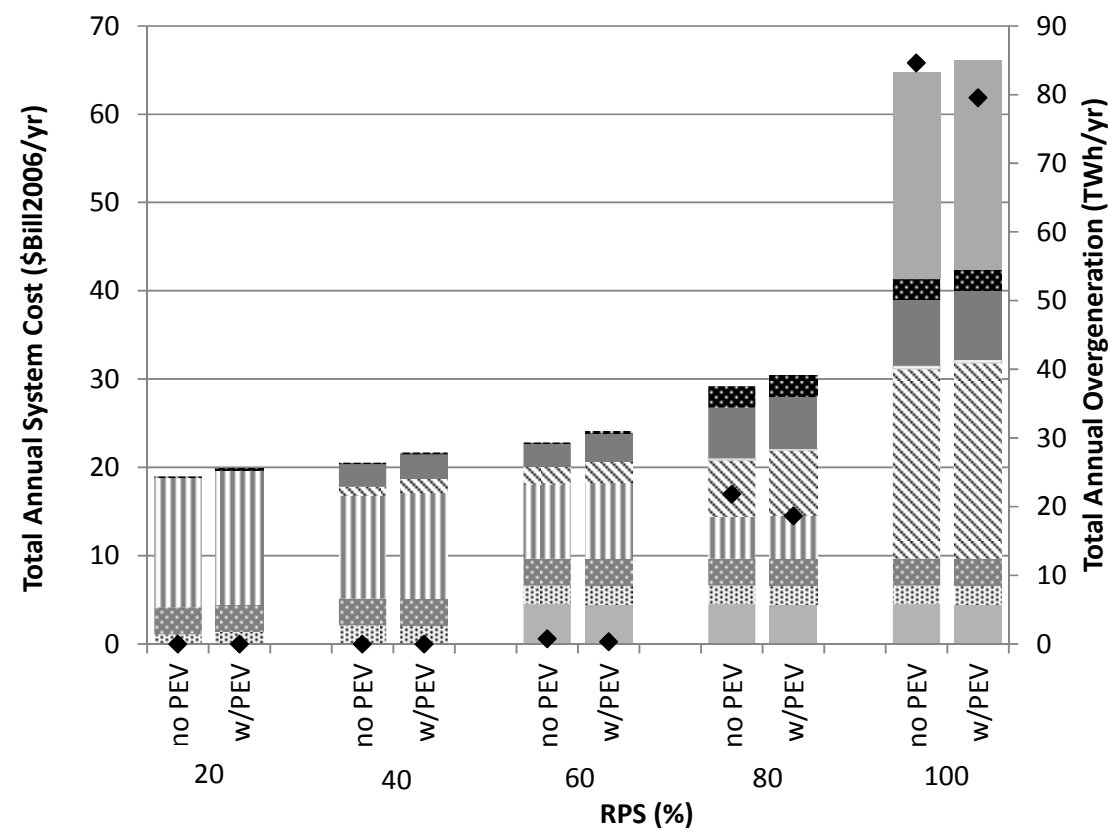

Battery

Pumped Hydro

CSP TES

Wind

Offshore Wind

Res PV

L Lg-Scale PV

x Coal

III Natural Gas

Conv Hydro

ROR Hydro

Geothermal

Nuclear

- Overgeneration

Figure 5 Total annual system cost and renewable overgeneration for AllCA with and without PEV load by RPS target. Values are based on a representative subset of 56 days with overgeneration. Total load 307 TWh/year with PEV load and 287 TWh/year without.

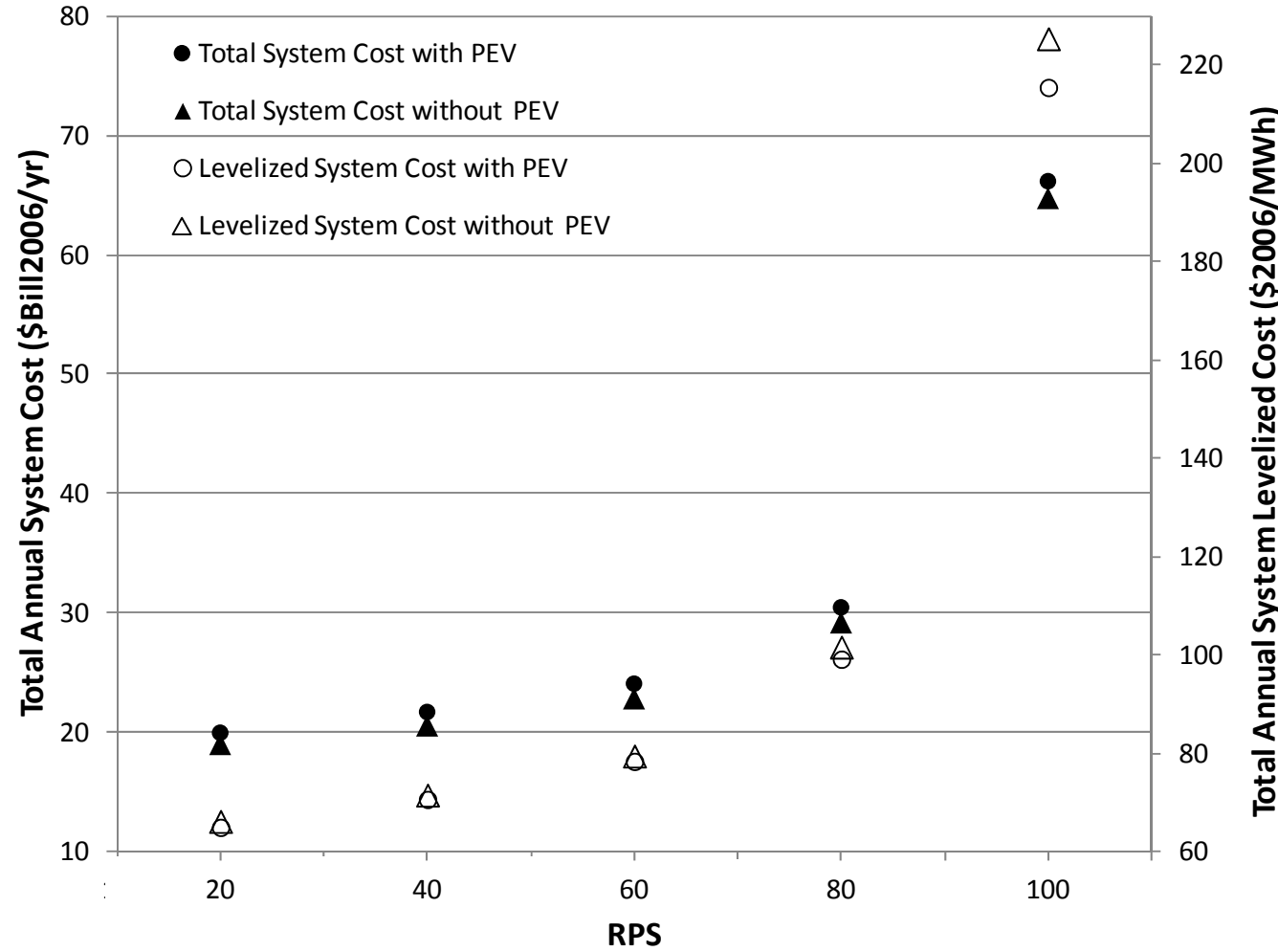

Figure 6 Total and levelized cost for AllCA region with and without PEV load for various RPS targets. Levelized cost values are based on served load (total generation minus curtailments). All values are based on a representative subset of 56 days with overgeneration. 


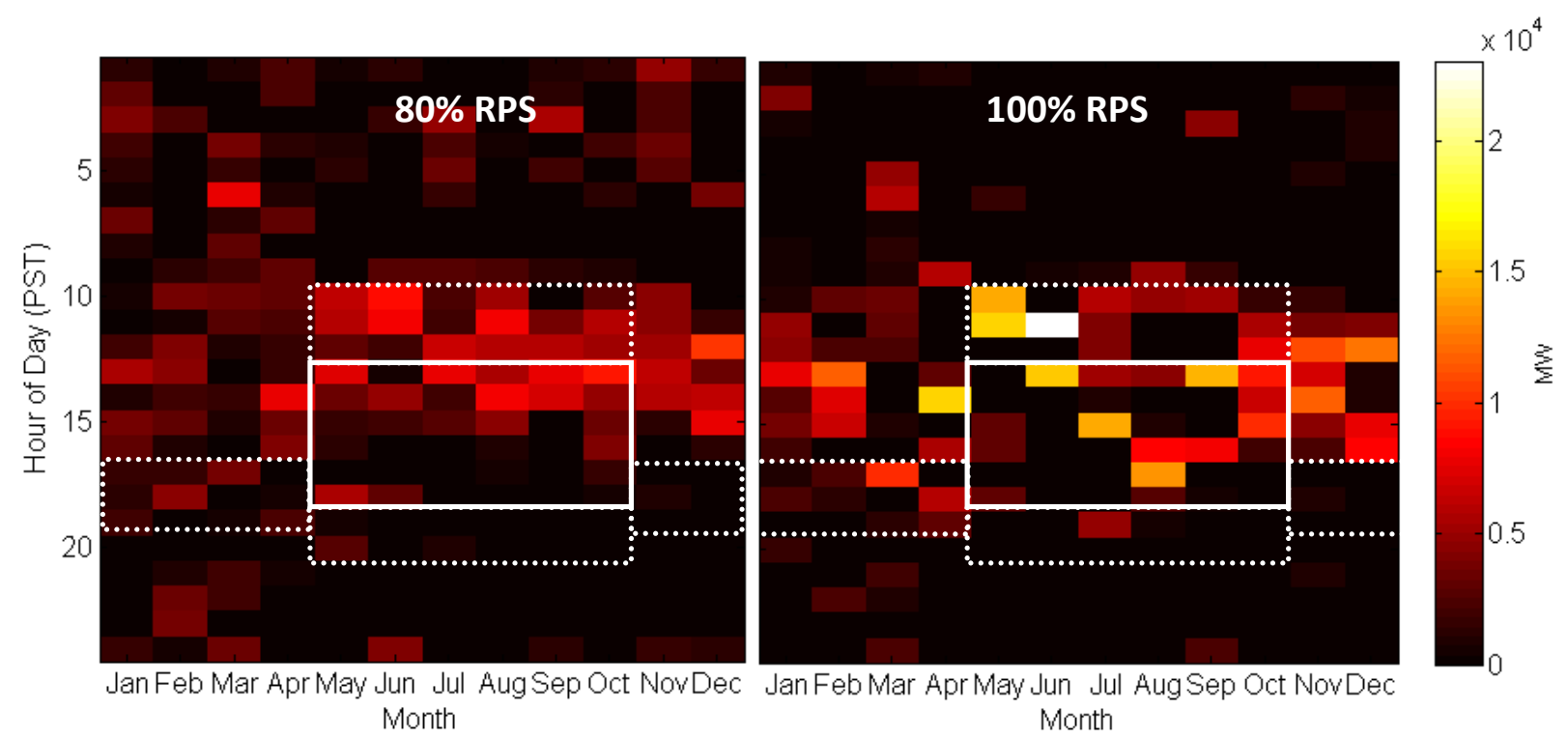

Figure 7 Comparison of average PEV flexible load with existing TOU rate structure for AllCA with $80 \%$ and $\mathbf{1 0 0} \%$ RPS targets. Peak periods marked by the solid white lines (May-October 1-7pm) and part-peak by dashed white lines (weekdays only, May-October 10am-1pm and 7-9pm, and November-April 5-8pm), both for the PG\&E Residential TOU E6 rate structure. Values are based on a representative subset of 56 days with overgeneration. 

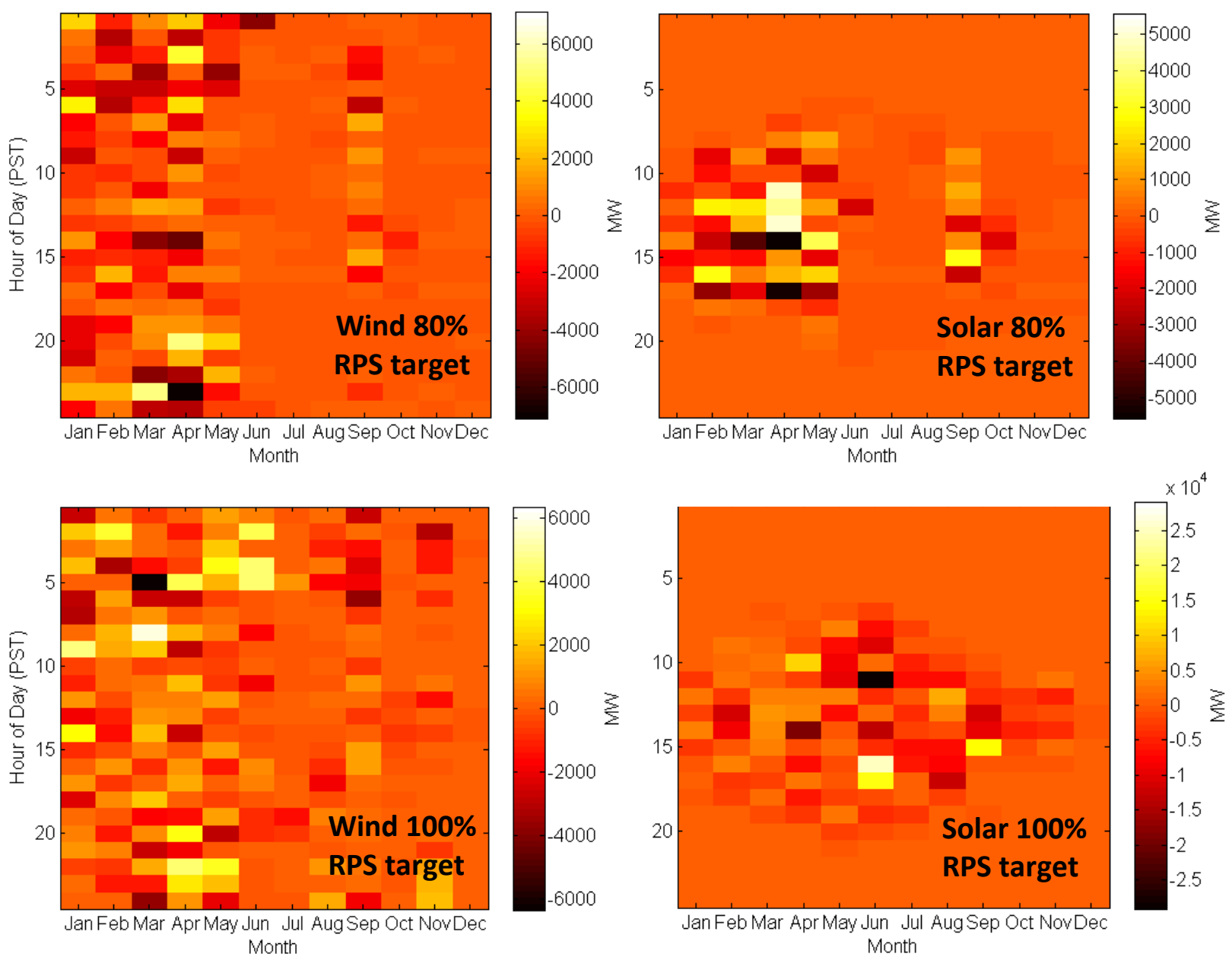

Figure 8 Difference in renewable overgeneration due to PEV for AlICA at $80 \%$ and $100 \%$ RPS targets. Wind includes onshore and offshore; solar includes large-scale and residential PV. Hourly overgeneration values were assigned to wind and solar based on the relative production of each in that hour. Values show (PEV - non-PEV) difference and are based on a representative subset of 56 days. Note that colorbar scales are not consistent. 


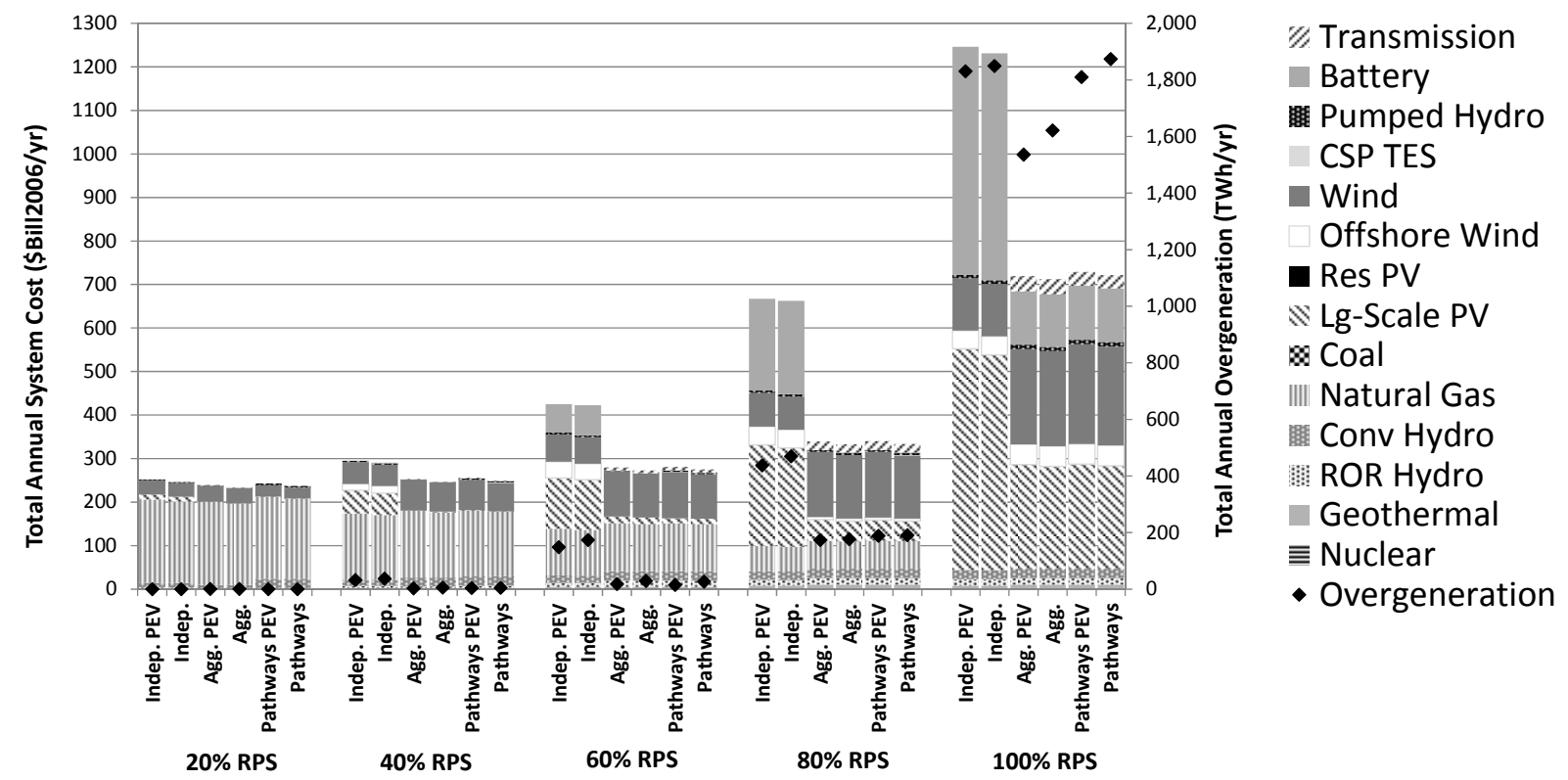

Figure 9 Total annual system cost and renewable overgeneration for US system with different RPS targets. For each RPS target, results are shown for ( $L$ to R): independent FERC regions with PEV load, independent FERC regions without PEV load, aggregated (interconnected) FERC regions with PEV load, aggregated regions without PEV load, pathways buildout of aggregated regions with PEV load, and pathways buildout of aggregated regions without PEV load. All runs used the same 14 representative days; independent and aggregated regions did not include CSP TES, but pathways aggregated regions included a relaxed formulation of CSP TES. 


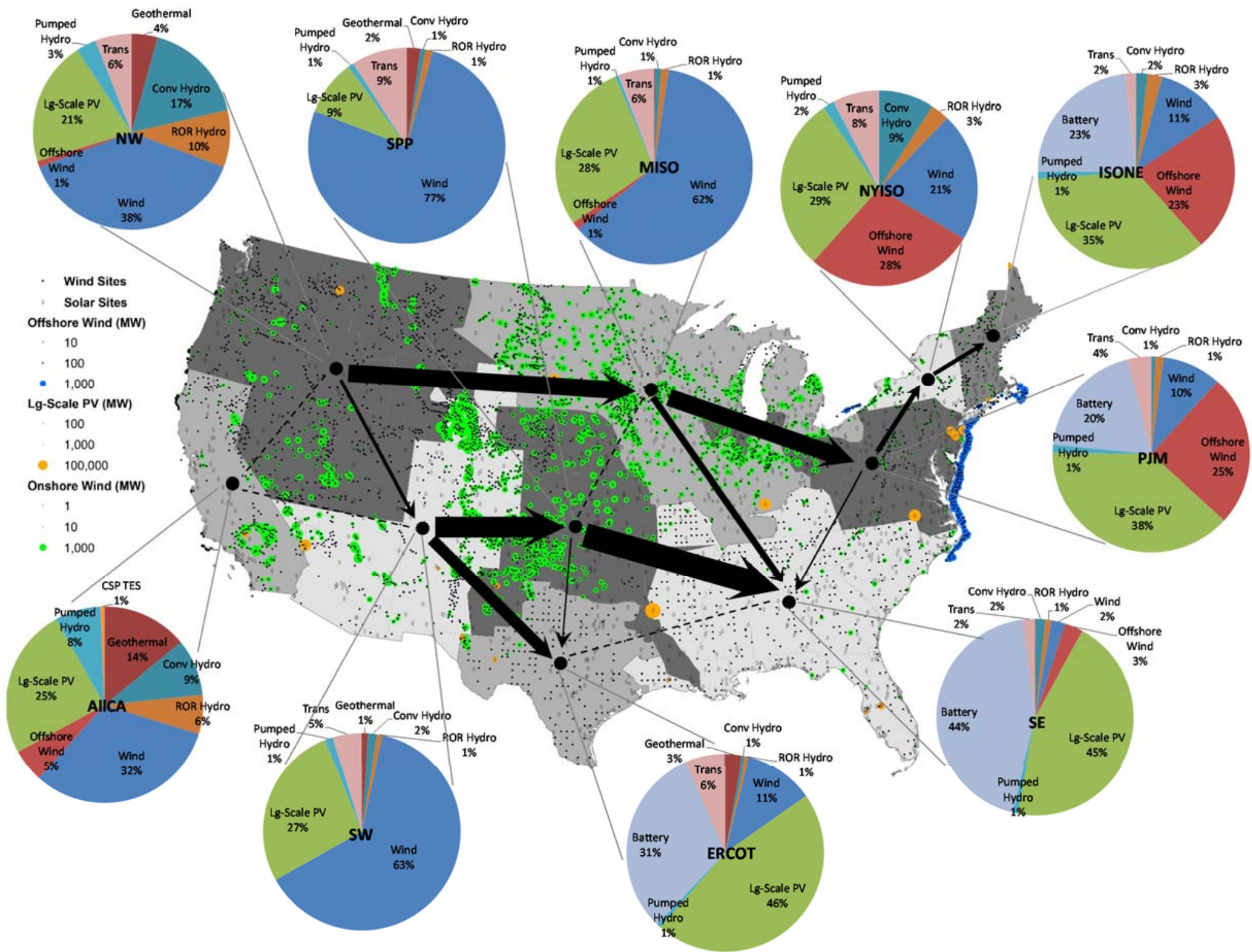

Figure 10 Breakdown of total annual system cost, wind and solar site buildouts, and new additional transmission capacity required for pathways buildout of aggregated (interconnected) US system with a 100\% RPS target without PEV load. Pie charts show relative contribution of each built generator and storage technology to the total annual cost in each region. Arrows show dominant direction of transmission, and weight of line shows relative magnitude of new capacity, with the largest magnitude being 75.7GW from SPP to SE. Dashed lines represent no new required capacity. Results are based on 14 representative days with relaxed formulation of CSP TES. 


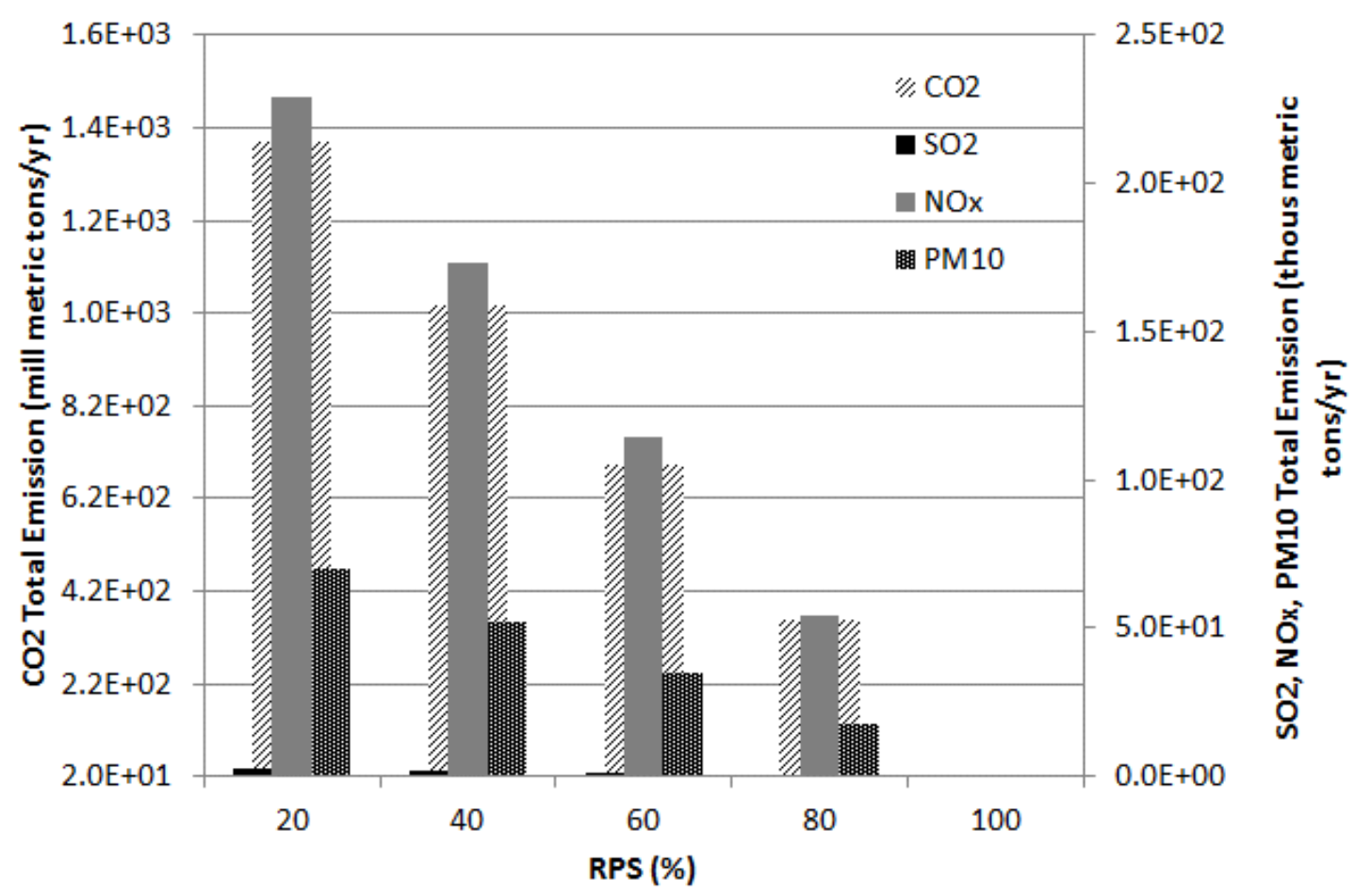

Figure 11 Total annual emissions by RPS target for aggregated US pathways buildout without PEV load. $\mathrm{CO}_{2}$ on left axis, all others on right. All runs used the same 14 representative days with relaxed formulation of CSP TES. 